Brit. J. soc. Med. (1947), 2, 73-125.

\title{
STUDIES ON INFANT MORTALITY
}

\author{
BY \\ BARNET WOOLF, M.A., Ph.D. \\ (From the Zoology Department, University of Birmingham)
}

\section{PART II.* SOCIAL AETIOLOGY OF STILLBIRTHS AND INFANT DEATHS IN COUNTY BOROUGHS OF ENGLAND AND WALES}

(Received April 20, 1946)

\section{INTRODUCTION}

The object of this series of papers is to give as complete and detailed a quantitative account as the data allow of the way in which infant mortality and stillbirth rates are influenced by social conditions. In the first paper (Woolf and Waterhouse, 1945) multiple regression equations were given showing the relation between the infant mortality rate and five indices of social conditions in the county boroughs of England and Wales for the eleven years 1928 to 1938 inclusive. The indices used were:

H: Percentage of families living more than one person per room (Census, 1931).

U: Average monthly percentage unemployment among adult males (Ministry of Labour, “ Local Unemployment Index ").

P: Percentage of occupied males in Social Classes IV (semi-skilled workers) and V (unskilled workers) (Census, 1931).

F: Percentage of females aged 14 and over employed in manufacture (Census, 1931).

L: Degrees of latitude north of $50^{\circ} 30^{\prime}$.

Thus $\mathrm{H}$ is an index of overcrowding, $\mathrm{U}$ and $\mathrm{P}$ are measures of low income, $\mathrm{F}$ is an estimate of industrial employment of mothers, and $\mathrm{L}$ is an expression of geographical position and of all the differences in social conditions associated therewith. Some thirty possible social indices were tried, and these five were selected because they seemed in combination to give the highest degree of concordance between observed infant mortality rates and those calculated from the equations.

Separate equations were computed for each of the eleven years, as well as two that summarized in different ways the experience of the whole period. Both the internal consistency of the results from year to year and the concordance between the observed rates and those calculated from the equations were remarkably high. For individual years the multiple correlation coefficient varied between 0.63 and 0.85 , while for the equation showing the dependence on the five social indices of

\footnotetext{
* Part I of this study appeared in the Journal of Hygiene (Cambridge) in 1945, vol. 44, p. 67.
} 
the mean infant mortality during the whole eleven-year period, the multiple correlation coefficient was $\mathbf{0 \cdot 8 8}$. The average equation for the whole period was as follows:

$$
\mathrm{M}=23 \cdot 1+0 \cdot 51 \mathrm{H}+0 \cdot 46 \mathrm{U}+0 \cdot 29 \mathrm{P}+0 \cdot 35 \mathrm{~F}+2 \cdot 01 \mathrm{~L}
$$

From the various equations a detailed balance sheet of infant deaths was drawn up and a number of calculations were made, which may be broadly summarized as follows:

The infant mortality rate to be expected if overcrowding, low income, and industrial employment of women could have been entirely eliminated was $23 \cdot 1$. The difference between this figure and the observed mean rate of 65.4 represents preventable deaths. Of these, about one-third were associated with overcrowding, one-quarter with low-paid occupations, one-fifth with unemployment, and oneeighth with industrial employment of women.

The paper by Woolf and Waterhouse contained statistical tests showing the undoubted significance of the various parameters, and social and medical reasons for regarding the relation between infant mortality and the social variables as a real one, in the sense that improvements in social conditions might really be expected to reduce infant deaths. But the paper did not deal with questions of social aetiology, of how overcrowding, low earnings, and so on actually exert their influence on the life of the baby. The total infant mortality is a complex phenomenon, made up of deaths at different periods of the first year of life attributable to different diagnostic categories. The previous paper expressly postponed discussion of aetiology until the total mortality had been dissected by age at death and by cause as stated on the death certificate. This further analysis has now been carried out, and the present paper gives regression equations for the separate diagnostic groups and age-periods during which death occurs. The number of social indices has also been increased to seven by the addition of one expressing the size of family and another measuring the local density of population. The present paper also deals with stillbirths.

The degree to which total infant mortality can be subdivided for purposes of analysis obviously depends upon the availability of the relevant figures. For age at death in county boroughs the information is given in considerable detail. In every yearly issue of Part I of the Registrar-General's " Statistical Review " over the period 1928 to 1938 there is a table giving for each county borough the actual numbers of infants reported as dying at ages: under 1 day, 1 to 7 days, 1 to 4 weeks, 4 weeks to 3 months, 3 to 6 months, 6 to 9 months, and 9 to 12 months. From these figures and those for total live births, death-rates per 1,000 births can be calculated for each of the seven specified periods of the first year of life. For the analysis by cause of death, however, the published data are not quite so favourable. The only figures available for the individual county boroughs are contained in a table giving actual numbers of registered deaths at various ages throughout the whole span of life, divided into 32 cause categories until 1930, and 
thereafter into 36 groups. Most of these categories relate to deaths in higher agegroups, so the information about infants is not very detailed. It is particularly unfortunate that a number of different causes responsible for the majority of neonatal deaths are lumped together under the one heading of " congenital causes, etc." Nor is there any tabulation for individual county boroughs of deaths by cause at different periods of infancy. More detailed analyses are available for the country as a whole, and for various larger subdivisions by geographical region, type of municipal area, and occupation and social class of the father. Some of the valuable ancillary information in these tables will be presented in the next section, as an introduction to the regression equations for the county boroughs.

\section{Infant Mortality by Cause and Age at Death}

Causes of infant death, as stated on the death certificate, may conveniently be classified under the following five headings: (1) "Developmental and Wasting Diseases " which are sometimes referred to by the Registrar-General as "Congenital Causes". (2) "Infectious Diseases". (3) "Bronchitis and Pneumonia". (4) "Diarrhoea and Enteritis". (5) "Other Causes". The main individual diagnostic categories included under these headings, and their contributions to the infant mortality rate, are shown in Table I.

As will be seen from the table, the Registrar-General's grouping of " Developmental and Wasting Diseases" comprises five separate causes. But sometimes the heading is " Congenital Causes," in which case it may include also some or all of the following: injury at birth, diseases of the umbilicus, pemphigus neonatorum, and other diseases of early infancy. As the table shows, the addition of these items would put only an extra 3.01 on to the death-rate in this group, bringing the total from 28.53 to $31 \cdot 54$. Nevertheless, this variation in methods of grouping and tabulation is apt to cause difficulties and confusion unless the items included under a general heading are always verified. It is unfortunately not always possible from the published data to adjust the figures from different official tables and reports so as to make them refer to the same list of causes of death.

Similar caution is necessary in interpreting figures for the infectious disease group. In his annual " Statistical Review" the Registrar-General classifies under the title "Common Infectious Diseases" the following: measles, whoopingcough, diphtheria, scarlet fever, varicella, smallpox. Table I shows that in this group the most important are measles and whooping-cough, which together account for 2.79 out of the total mortality rate of 2.99. But in the 1931 Decennial Supplement, the heading "Infectious Diseases" covers a much wider field. If one adds only three important diseases-influenza, menirgitis, and cerebrospinal-fever-it will be seen from Table $I$ that the death-rate in this group is increased by 1.20 from 2.99 to $4 \cdot 19$. Here again it is not safe to compare the death-rates from different tables or reports without a preliminary inquiry as to the actual diseases grouped under the general heading. 
"Bronchitis and Pneumonia" is not a group heading used by the RegistrarGeneral. He usually includes these diseases in his group of miscellaneous causes of death. But they make such an important contribution to the mortality rate-

TABLE I

Infant Mortality by Cause: Mean Death-Rates per 1,000 Live Births, England and WALES, 1928-1938

"Developmental and Wasting Diseases":

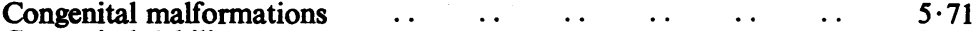

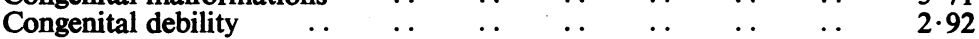

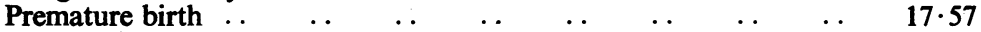

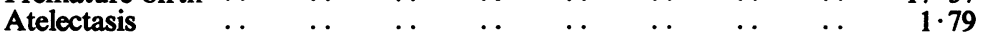

$\begin{array}{lllllllll}\text { Icterus neonatorum } & \ldots & \ldots & \ldots & \ldots & \ldots & \ldots & \ldots & 0.54\end{array}$

"Congenital Causes," in addition to above:

Total

$\begin{array}{llllllllll}\text { Injury at birth } & . . & . . & \ldots & \ldots & \ldots & . . & . & \ldots & 2.27\end{array}$

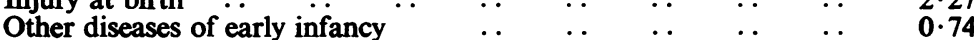

$$
\text { Total }
$$

"Common Infectious Diseases":

Measles

Whooping cough

Diphtheria

Others

$\ldots$
$\ldots$
$\ldots$

Other Infectious Diseases:

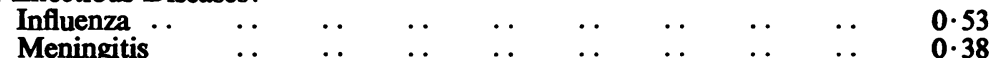

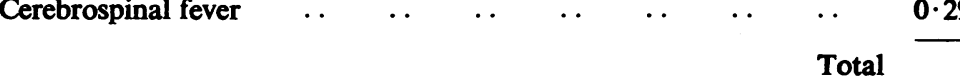

“Bronchitis and Pneumonia ":

$\begin{array}{llllllllll}\text { Bronchitis } & . & \ldots & \ldots & \ldots & \ldots & \ldots & \ldots & \ldots & 2.67\end{array}$

$\begin{array}{llllllllll}\text { Pneumonia } & . & \ldots & \ldots & \ldots & \ldots & \ldots & \ldots & \ldots & 9.45\end{array}$

Total

$12 \cdot 12$

$\begin{array}{lllllllll}\text { “Diarrhoea and Enteritis ": } & \ldots & \ldots & \ldots & \ldots & \ldots & \ldots & \end{array}$

..

$\begin{array}{llllllllll}\text { Convulsions } & . & \ldots & \ldots & \ldots & \ldots & \ldots & \ldots & \ldots & 1.90\end{array}$

$\begin{array}{lllllllll}\text { Tuberculous diseases } & . . & \ldots & \ldots & \ldots & \ldots & \ldots & \ldots & \mathbf{0 . 8 2}\end{array}$

$\begin{array}{llllllll}\text { Hernia, intestinal obstruction } & . . & \ldots & \ldots & \ldots & \ldots & \ldots & 0.57\end{array}$

$\begin{array}{llllllllll}\text { Suffocation } & . & . . & . . & . . & \ldots & \ldots & \ldots & \ldots & 0.47\end{array}$

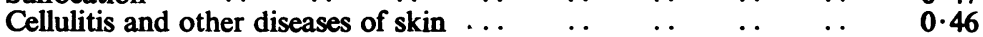

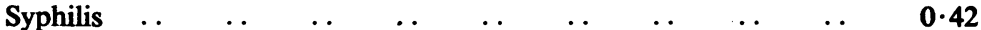

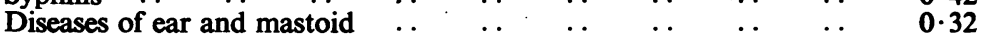

$\begin{array}{lllllllll}\text { Inattention at birth } & \ldots & \ldots & \ldots & \ldots & \ldots & \ldots & \ldots & \mathbf{0}\end{array}$

$\begin{array}{llllllll}\text {-Inflammation of stomach } & . & \ldots & . . & \ldots & \ldots & \ldots & \mathbf{0} \cdot 30\end{array}$

$\begin{array}{llllllll}\text { Other respiratory diseases } & . . & \ldots & \ldots & \ldots & \ldots & \ldots & \mathbf{0} \cdot 23\end{array}$

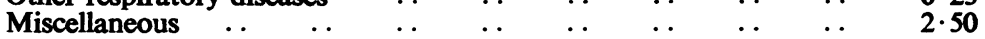

$$
\begin{array}{llllllll} 
& & & & & \text { Total } & \\
\text { Total infant mortality } & \ldots & \ldots & \ldots & \ldots & \ldots & \mathbf{8 1 \cdot 7 1}
\end{array}
$$

nearly $20 \%$ of the total-that it seemed desirable in this paper to single them out for separate investigation. Sometimes pneumonia is given as "pneumonia, all forms", and sometimes "bronchopneumonia" is separately tabulated. In this 
paper bronchopneumonia is included under the term " pneumonia". The heading "Diarrhoea and Enteritis" calls for no special comment. "Other Causes" is of course the most unstable of all the group headings, as its content depends on what is included in or left out of all the other groups. In the Registrar-General's annual Statistical Review, the content of the "Miscellaneous Diseases" group differs widely from " Other Causes" as given in Table I. He does not include tuberculous diseases, which he tabulates separately. On the other hand, he does include injury at birth and other diseases of early infancy, all the infectious diseases such as influenza and meningitis, left out of his list of common infectious diseases, and also bronchitis and pneumonia.

In this paper the individual causes included in a general group will always be indicated, especially when comparisons are being made between official figures that may have been differently classified and tabulated. For the time being, the tabulated causes of death will be taken at their face value. The probable degree of reliability of the different diagnostic categories will be discussed in a later section.

In Table I are shown the average yearly death-rates attributed to the main individual causes and groups of causes, for the whole of England and Wales during the eleven years 1928 to 1938 . Table II shows the percentage of the total death-rate

TABLE II

Infant Mortality by Cause: Percentages of Total Rate, England and Wales, 1928-38

Congenital Causes:

Registrar-General's " Developmental and Wasting Diseases" .. $46.2 \%$

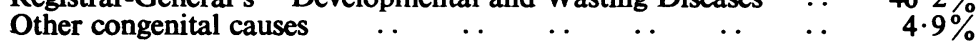

$\begin{array}{lll}\text { Infectious Diseases: } & \text { Total } & 51 \cdot 1 \%\end{array}$

Registrar-General's "Common Infectious Diseases"

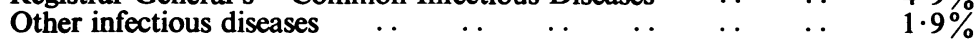

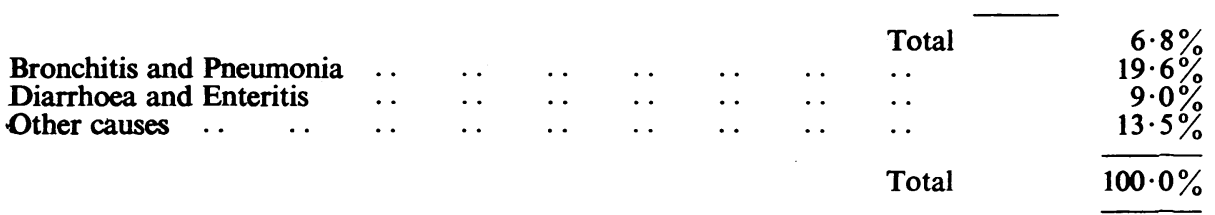

for each group of causes. It will be seen that the most important group is " Congenital Causes ", responsible for over half the deaths. Within this group the largest individual item is premature birth, with a rate of 17.57 , constituting $28.5 \%$ of the total mortality. The next largest group is " Bronchitis and Pneumonia ", covering almost one-fifth of all deaths. "Diarrhoea and Enteritis" accounts for about one-eleventh of the deaths, and "Infectious Diseases" for about one-fifteenth. Whooping-cough is the most deadly disease in this group, followed in diminishing order by measles, influenza, meningitis, cerebrospinal fever, and diphtheria. Among "Other Causes" the largest single item is convulsions-an uncertain and unsatisfactory diagnostic category whose occurrence on death certificates is steadily 
diminishing. "Tuberculous Diseases," formerly a prominent cause of infant deaths, has now become a relatively minor class, with a rate of 0.82 . A big improvement in the general standard of mothercraft is indicated by the rates for suffocation and inattention at birth, which together amount to 0.78 -a figure that is of course much too high, but nevertheless is a great advance on the state of affairs. even a generation ago. The average number of births per annum for the period 1928 to 1938 was about 613,000 , so that a death-rate of 1 corresponds to about 613 deaths a year.

Risk of death is greatest immediately after birth, and diminishes steadily thereafter. Table III gives the figures for England and Wales during the period

TABLE III

Infant Mortaltty by Age at Death: MEAn Death-Rates Per 1,000 Live Births, England AND WALES, 1928-38

\begin{tabular}{|c|c|c|c|c|}
\hline Age at Death & $\begin{array}{c}\text { Mortality } \\
\text { Rate }\end{array}$ & $\begin{array}{c}\text { Cumulative } \\
\text { Mortality } \\
\text { Rate }\end{array}$ & Percentage & $\begin{array}{l}\text { Cumulative } \\
\text { Percentage }\end{array}$ \\
\hline 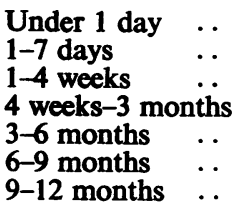 & $\begin{array}{l}10 \cdot 51 \\
11 \cdot 58 \\
8 \cdot 83 \\
9 \cdot 83 \\
8 \cdot 54 \\
6 \cdot 66 \\
5 \cdot 76\end{array}$ & $\begin{array}{l}22 \cdot 09 \\
30 \cdot 92 \\
40 \cdot 75 \\
49 \cdot 29 \\
55 \cdot 95 \\
61 \cdot 71\end{array}$ & $\begin{array}{r}17 \cdot 0 \\
18 \cdot 8 \\
14 \cdot 3 \\
16 \cdot 0 \\
13 \cdot 8 \\
10 \cdot 8 \\
9 \cdot 3\end{array}$ & $\begin{array}{r}35 \cdot 8 \\
50 \cdot 1 \\
66 \cdot 1 \\
79 \cdot 9 \\
90 \cdot 7 \\
100 \cdot 0\end{array}$ \\
\hline Total $\ldots$ & $61 \cdot 71$ & & $100 \cdot 0$ & \\
\hline
\end{tabular}

1928-38. Deaths on the first day were $17 \%$, or more than one-sixth, of those during the whole first year of life. Deaths in the first four weeks are often referred to as neonatal deaths. The neonatal rate was $30 \cdot 9$, just over half the total infant mortality. Almost two-thirds of the deaths occurred during the first three months. of life, and four-fifths in the first six months. For the four quarters the rates were respectively $40 \cdot 75,8 \cdot 54,6 \cdot 66$, and $5 \cdot 76$, and the respective percentages were $66 \cdot 1,13 \cdot 8,10 \cdot 8$, and $9 \cdot 3$.

In the Registrar-General's Decennial Supplement (D.S., 1931) there are tables showing how infantile mortality from different causes and at different ages varies with the social class of the father. The occupied male population was divided into five social classes. Class I contained the upper and middle class, Class III skilled labour; and Class V unskilled labour. The other two were intermediate-Class II including roughly the lower middle class, and Class IV semi-skilled labour. All deaths of legitimate infants during the three-year period 1930-2 were assigned to the appropriate social class according to the father's occupation as stated on the death certificate, and the average numbers of yearly deaths were related to live births within the social class registered in 1931. Mortality rates per 1,000 live births 
by cause groups for each social class are shown in Fig. 1. "Congenital Causes" comprises all the items shown under the first two headings in Table I, and "Infectious Diseases" covers a comprehensive list including all the diseases under headings "Common Infectious Diseases" and "Other Infectious Diseases" in Table I, with the exception of meningitis. "Other Causes " in the figure differs slightly from the list in Table I, since deaths from meningitis have to be added and a few deaths from the rarer infectious diseases have to be subtracted. All these adjustments, however, are quite small, and the cause groups in the figure are substantially the same as those shown in Tables I and II. Another consideration affecting strict comparability is the fact that Tables I and II refer to all infants

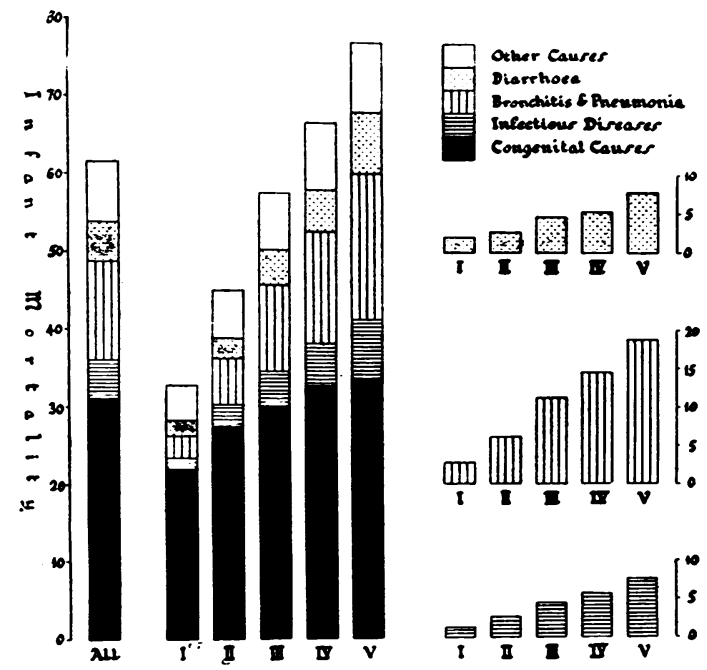

Fig. 1.-Infant mortality analysed by cause groups in social classes of England and Wales, 1930-32.

born during 1928-38, while Fig. 1 relates only to legitimate infants during 1930-2, though here again the differences are very small and do not affect the general conclusions.

For infant mortality as a whole and for each group of causes there is a steady increase in the rate between Class I and Class V, but the relative disparities differ greatly for the various diagnostic headings. "Congenital Causes" shows by far the smallest relative class gradient, the ratio of the rates for Class V and Class I being approximately 1.5:1. The greatest contrast occurs in the bronchitis and pneumonia group, where the rate for Class $V$ is about $6 \frac{3}{4}$ times that for Class $I$. Next comes the infectious diseases group, with a ratio of about 5.4: 1 , and then diarrhoea, with a disparity of nearly $4: 1$. For "Other Causes" the ratio is $2: 1$. Because of these differing ratios, the relative importance of the cause groups alters as one passes down the social scale. Congenital causes, for example, were responsible for over two-thirds of the deaths in Class I and about three-sevenths in Class V, 
as compared with the national average of just over half the deaths. Conversely, bronchitis and pneumonia, which have the steepest class gradient, were assigned as the causes of about one-quarter of the deaths in Class $\mathbf{V}$ as compared with about one-twelfth in Class I. There is a steady increase in mortality with increasing poverty for every individual cause listed by the Registrar-General, with two exceptions, both of which are included in the " congenital causes" group. One is congenital malformations, which is substantially the same in Classes II to V, though the rate in Class I is a little lower. The other is injury at birth, which is. slightly in excess in Classes I and II as compared with Classes IV and V.

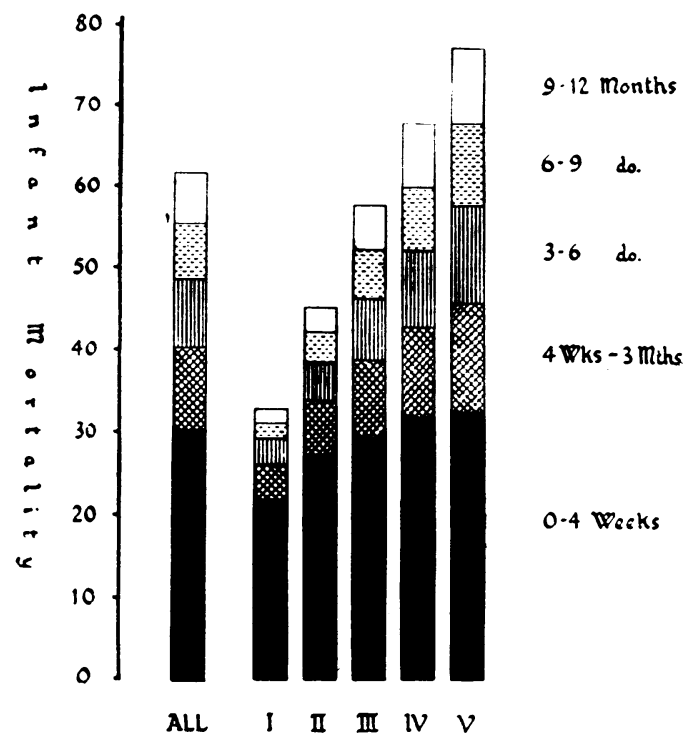

Fig. 2.-Infant mortality analysed by age at death; social classes of England and Wales, 1930-23.

Fig. 2 depicts the social class mortalities divided according to age at death. The rates are given for five periods of infancy-from birth to 4 weeks old, often called the neonatal deaths; 4 weeks to 3 months; 3-6 months; 6-9 months; and 9-12 months. During each of these periods there is a class gradient, but it grows relatively steeper as the baby gets older. For the neonatal period the ratio of Class $\mathrm{V}$ to Class $\mathrm{I}$ is $1 \cdot 5: 1$. For the remainder of the first quarter, it is about 3:1. During the second quarter, infants in Class $V$ have nearly four times the death-rate of infants in Class I, and during the third and fourth quarters the disparity is about 5.4: 1. Neonatal deaths are about half the total for all classes combined, two-thirds for Class I, and three-sevenths for Class V. The figures for neonatal deaths correspond very closely to those for deaths from congenital causes.

It is instructive also to compare the mortality experience of babies born in large towns, in smaller towns, and in rural areas. For purposes of local government, 
the country is divided into county boroughs, municipal boroughs, urban districts, and rural districts. The county boroughs are the larger towns, mostly with populations of over 50,000. At the time when the local government divisions were made, the municipal boroughs were the smaller towns, urban districts were areas of predominatingly urban character, and rural districts were mainly country. Later extensions of industrial and residential building have in many cases altered the character of local government divisions, and although the municipal classifications are subject to revision there is a big time-lag between the growth of a village into a town and a corresponding change in local government status. In particular, it frequently happens that urban districts are really the outer suburbs of a large town or conurbation of towns, while rural districts, especially in the mining areas, may quite often be densely populated and primarily industrial. London forms an

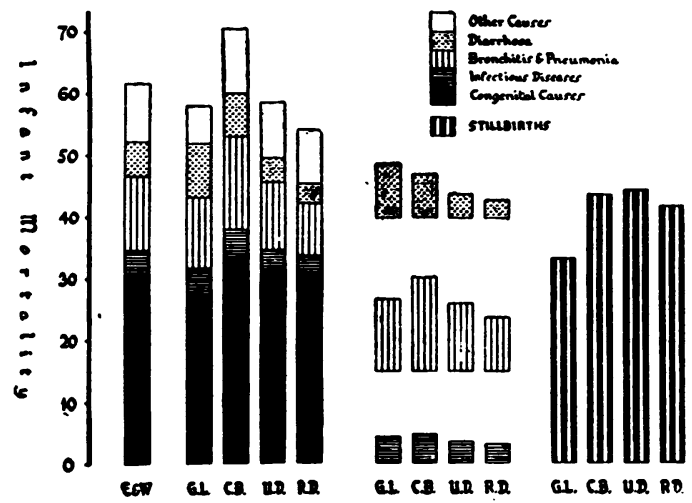

Fig. 3.-Infant mortality analysed by cause groups, and stillbirths, in different types of local government areas, England and Wales, 1928³8.

E \& W =England and Wales. G.L.=Greater London. C.B. =County boroughs outside Greater London. U.D.=Other urban districts outside Greater London. R.D. = Rural districts.

exception to these municipal arrangements. The inner portion is the administrative county, divided into 29 semi-autonomous boroughs, and the outer built-up ring is carved into municipal boroughs and urban districts whose boundaries are based upon past conditions and have no relation to present social realities. It is nevertheless true that rural districts, taken as a whole, cover the agricultural population and its ancillaries with some admixture of mining, outer suburban, and other urban elements; urban districts and municipal boroughs are less densely populated than county boroughs; and these in turn are on the whole relatively small towns compared to the continuous built-up area of Greater London, with its population of over $8,000,000$.

In his annual Statistical Review the Registrar-General gives infant mortality rates, subdivided by cause and by age at death, for the following four aggregates of municipal areas: (1) Greater London; (2) County Boroughs outside Greater 
London; (3) Other Urban Districts, comprising "municipal boroughs" and " urban districts" outside Greater London; (4) Rural Districts outside Greater London. This classification dates from 1931. Until 1930 the method of subdivision was slightly different, but not so as materially to affect comparability with the later series of figures.

Fig. 3 shows the average infant mortality rate during the eleven-year period 1928-38 for England and Wales as a whole and for the four types of municipal area, subdivided according to cause of death. A few minor items included in "Congenital Causes" in Fig. 1 are excluded in Fig. 3, and the "Infectious Diseases" group also differs in that it does contain meningitis and does not contain some very rare infectious conditions. But, on the whole, the categories in Figs. 1 and 3 are reasonably comparable. Fig. 3 also shows stillbirth rates. To make them comparable with the infant mortality rates they are calculated per 1,000 live births.

The phenomena displayed in Fig. 3 may be summarized as follows:

For total infant mortality, the order is county boroughs, urban districts, Greater London, rural districts. The rate for county boroughs, $\mathbf{7 0} \cdot 8$, is 12 units higher than that for urban districts. Urban districts and London had approximately the same mortality, and rural districts had a rate more than 4 units lower.

For congenital causes and also for other causes, London had by far the lowest rate. County boroughs had the worst figure, then urban districts, and then rural districts, but the rates for the three extra-metropolitan divisions differed little among themselves compared with the gap between them and London.

For infectious diseases and also for bronchitis and pneumonia, county boroughs were worst, followed by London, urban districts, rural districts.

For diarrhoea, London was markedly worse than county boroughs. There must be some radical difference in social aetiology between diarrhoea on the one hand and infectious diseases and bronchitis and pneumonia on the other, since diarrhoea is the only category where the death rate goes up with increasing degree of urbanization.

The relative distribution of stillbirths resembles that of congenital causes, except that urban districts are slightly higher than county boroughs. The superiority of London over the other areas is even greater for stillbirths than for congenital causes.

London is best for stillbirths, congenital causes, and other causes, and worst for diarrhoea. County boroughs are worst for everything except stillbirths and diarrhoea. Stillbirths are highest in urban districts, but county boroughs run them close. Rural districts are best for infectious diseases, bronchitis and pneumonia, and diarrhoea. The child born in the country thus has the least risk of death from zymotic diseases, while the London baby fares best in relation to the risks of birth and early infancy.

Some of these results, such as the lower rates for the three infectious groups in smaller towns and rural areas, will probably seem obvious and natural. Other features, such as the low stillbirth and congenital rates and the high diarrhoea rate in London, may appear anomalous and puzzling. It will be shown below that these anomalies can be satisfactorily explained by the aetiological considerations suggested by the regression equations for the county boroughs.

When mortality in the four classes of administrative area is analysed according to age at death the results are quite regular. During the neonatal period county 
boroughs show the highest rate, followed closely by urban districts and rural districts, with London well behind. The difference between county boroughs and rural districts is $2 \cdot 1$; between rural districts and London it is $6 \cdot 3$. For the remainder of the first quarter and for the three subsequent quarters the order is

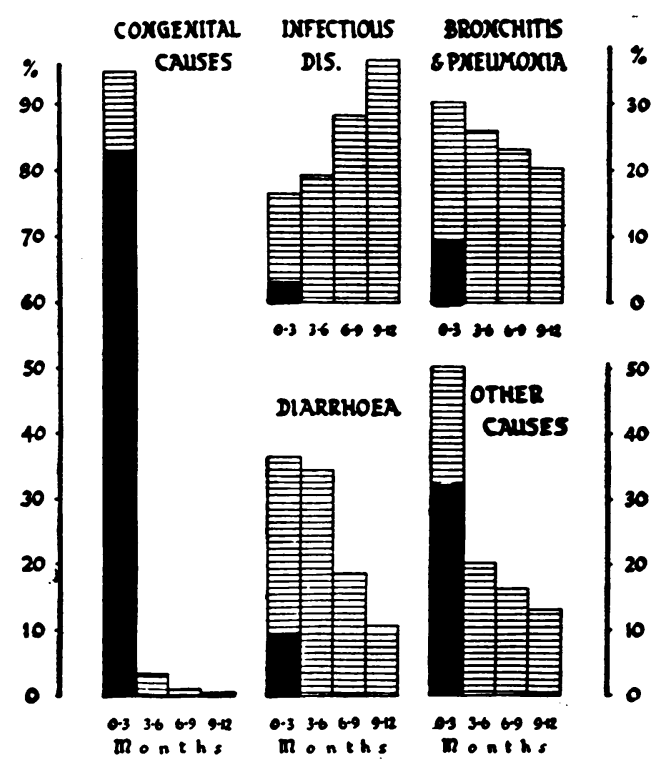

FIG. 4.-Mortality in each cause group divided according to age at death. Total mortality rate in each group is taken as 100 . Black area $=$ Neonatal rate $(0-4$ weeks). County boroughs, 1928-38.

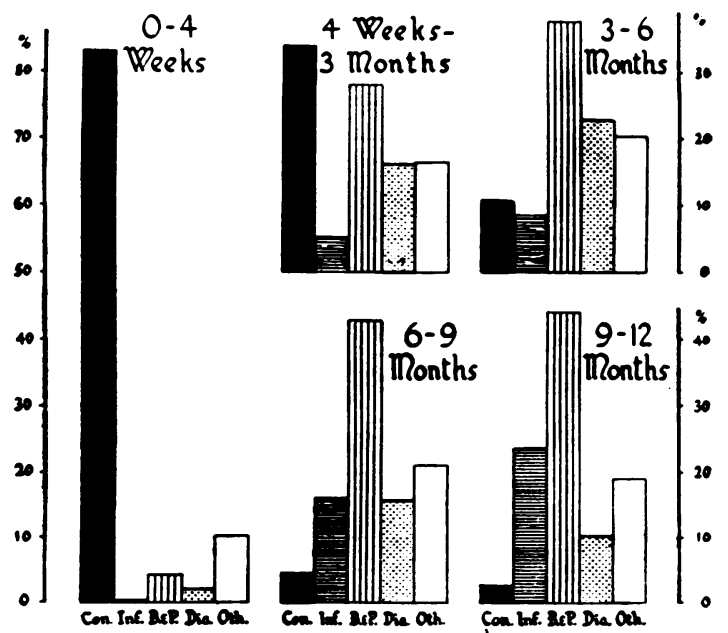

FIG. 5.-Mortality during various age periods during infancy divided according to cause group. Total mortality rate in each period is taken as 100 . County boroughs, 1928-38. 
county boroughs, London, urban districts, rural districts, just as it is for infectious diseases and for bronchitis and pneumonia.

The simultaneous analysis of infant mortality by cause and age at death is illustrated in Figs. 4 and 5. The data used are the mean rates during 1928-38 in county boroughs, but the figures for other types of area or England and Wales as a whole show the same essential features. In both figures the ordinates represent percentages of the relevant partial mortality rate. In Fig. 4 the mortality in each cause group is divided according to age at death. The solid black rectangle represents the percentage of the deaths occurring during the neonatal period, and the shaded area above it those during the remainder of the first quarter. It will be seen that the great majority of deaths from congenital causes occur during the neonatal period, deaths from infectious diseases increase with age, and deaths in the other cause groups go down. Fig. 5 shows the percentage of the deaths in each of the periods attributable to the various cause groups. In the neonatal period deaths from congenital causes greatly predominate, and these also claim the largest single share during the rest of the first quarter, with bronchitis and pneumonia a close second. Thereafter "bronchitis and pneumonia" is always in the lead, and as the baby gets older the relative importance of diarrhoea recedes and that of infectious diseases advances. It was seen from Fig. 1 that infectious diseases and bronchitis and pneumonia are the cause groups with the steepest class gradient. These become more and more relatively important as the baby grows older. It is therefore clear why Fig. 2 shows increasing disparity in relative class mortality with increase in age at death.

\section{Regression Equations for County Boroughs}

In order to estimate the influence of social conditions on stillbirths and on infant mortality at different ages and from different causes, multiple regression equations were computed by the product-moment method between the appropriate mortality rates for the individual county boroughs and the seven selected indices of social conditions. If $\mathbf{M}$ is the mortality rate for a county borough (technically the "dependent variable ") and A, B, C . . . are the numerical values for that borough of the various social indices (the "independent variables"), then the regression equation is of the general form:

$$
\mathbf{M}=\mathbf{K}+\mathbf{a A}+\mathbf{b B}+\mathrm{cC}+\ldots \ldots \ldots \pm \mathbf{d},
$$

where $a, b, c$. . . are constants (the " regression coefficients") and $d$ is the difference between the observed value of $M$ and that calculated from the regression equation. The mathematical procedure ensures that the constant $K$ and $a, b, c .$. are so fixed that $\Sigma d^{2}$ is a minimum. Woolf and Waterhouse (1945) give a full and critical discussion of the applicability of the method to the study of infant mortality, and of the effects of imperfections or errors in the raw figures on the trustworthiness of the equations obtained. Errors in the dependent variable, provided they are 
random and uncorrelated with the social indices, do not in general affect the equations, although they lower their degree of statistical significance. But imperfections in the independent variables will distort the equations, both by giving an incorrect picture of the relative influence of the various social conditions, and by underestimating the total effect of all the social indices acting together. Before the equations can be calculated, therefore, it is necessary to make a preliminary examination of all the variables with respect to their accuracy and relevance. They must be subjected to a process of social and medical questioning: How accurately do they measure the social phenomenon to which they allegedly refer; Are they likely to be relevant to the topic under investigation, and, if so, are they more closely applicable than any other available measure of the same phenomenon? This cross-examination of the data is aided and guided by objective mathematical tests. Out of various possible groups of indices of social conditions, that group is the most relevant which gives the highest multiple correlation with the dependent variable.

\section{Stillbirth and Infant Mortality Rates}

All the mortality rates used for the regression equations were calculated from figures of numbers of live births, stillbirths, and infant deaths in the individual county boroughs, as published in the annual Statistical Review of the RegistrarGeneral. The death-rate from each cause group or during each period of infancy was calculated thus:

$$
\frac{\text { Total relevant deaths during } 1928-38 \text { inclusive }}{\text { Total live births during } 1928-38 \text { inclusive }} \times 1,000
$$

Stillbirth rates were also calculated per 1,000 live births, to make them comparable with the various partial infant mortality rates. Since the number of births in each borough varies from year to year, rates calculated in this way will be slightly different from the average of the eleven yearly rates. In general, these pooled rates used in the regressions will be higher than the mean of the yearly rates, since mortality rates have tended to fall, and in the earlier years, when mortality was higher, there were also more births, giving these years a greater influence on the final figure.

As already stated, figures for death by age are given for seven subdivisions of the first year of life. These periods, with the symbols used in this paper, are as follows:

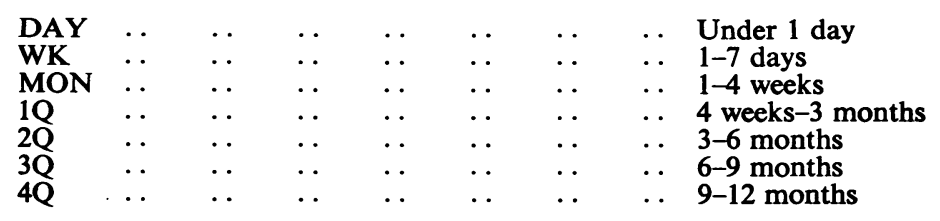


For death by cause, only an abridged list of causes is available, and this was revised in 1931. The groupings used in this paper, together with their symbols, are as follows:

CON .. The Registrar-General's category of " congenital causes, etc.," comprising all the items under the first two headings in Table I.

INF .. Infectious diseases, comprising

Typhoid and paratyphoid fevers (called "enteric fever" before 1931).

Measles.

Scarlet fever.

Whooping-cough.

Diphtheria.

Influenza.

Encephalitis lethargica.

B \& $\mathbf{P} \quad \ldots \quad$ Bronchitis and pneumonia.

DIA $\quad . \quad$ Diarrhoea.

OTH $\quad .$. Other causes, being total deaths less all those in above groups.

Total infant mortality will be denoted by the symbol IM and stillbirths by the symbol STI.

The ultimate source of all these figures is the individual birth, stillbirth, or death certificate, and it is necessary to inquire into the reliability of these certificates and of the rates calculated from them. It is of course possible that a few births are not registered at all, or that the date or other particulars are wrongly stated, but it seems likely that birth figures are on the whole highly accurate. One source of error is the difficulty of differentiating between a stillbirth and a death in the first few minutes of life. This will affect the precision of the figures for stillbirths and deaths on the first day, and to a much smaller proportionate extent the accuracy of the total number of live births. Stillbirth figures are subject to the further difficulty of drawing a firm line of demarcation between a stillbirth, defined as a foetus at least 28 weeks old since fertilization, and an abortion, defined as a foetus of lesser maturity. Similarly, deaths on the first day have a margin of error at both ends of the time scale: very early deaths may be confused with stillbirths, and deaths in the last hour or so may be wrongly classified because the exact time both of birth and of death cannot be stated without a margin of error that must be quite appreciable in comparison with the total period of 24 hours. A similar but smaller uncertainty must attach to the deaths for the 1-7 day period. After that, except in so far as dates of births and deaths may be wrongly stated, the error from this source is probably quite negligible.

Figures for cause of death are also subject to a degree of uncertainty which it is hard to assess. It must be very difficult in many cases for the doctor to assign the cause of infant death with any confidence, especially as necropsies are rarely performed. Some diagnostic categories, such as congenital debility or convulsions, are little more than a record of the presence of symptoms of unknown origin. Other conditions, such as pneumonia, bronchitis, and influenza, must be hard to differentiate, and the line of demarcation will vary from doctor to doctor. The margin of uncertainty will probably not be so great when causes are grouped as in 
this paper. The congenital group as a whole may be expected to be fairly easily distinguishable from the group of infectious diseases, while diarrhoea is also likely to be more or less uniformly diagnosed by different doctors. There is, however, much more doubt about the discrimination between infectious diseases and bronchitis and pneumonia, especially when lung infection is secondary to a disease in the infectious group. The Registrar-General has rules for selecting one cause when the certificate indicates multiple causation, but it seems likely, nevertheless, that a death that would be certified by one doctor so that it counted as measles or whooping-cough might be so described by another doctor that it counted as pneumonia. The "other causes" group, which includes some of the most dubious diagnostic headings, will also suffer from lack of precision.

In so far as differences in diagnostic practice are randomly distributed among boroughs and not correlated with poverty, overcrowding, or the other social indices, they will merely add to the error variance without imparting any systematic bias to the regression coefficients. There seems to be no special reason to suppose that method of certification will vary markedly with social conditions. It is fortunate that in the two cause groups most subject to errors of demarcationinfectious diseases and bronchitis and pneumonia-the relative influence of the various social indices as computed from the regression equations is so similar that moderate differences in certification procedure between the various county boroughs can have no appreciable distorting effect on the general conclusions.

TABLE IV

Infant Mortality and Stillbirth Rates Per 1,000 Live Births in County Boroughs, $1928-38$

\begin{tabular}{|c|c|c|c|c|c|c|c|}
\hline & $\begin{array}{l}\text { Unweighted } \\
\text { Mean }\end{array}$ & $\begin{array}{c}\text { Weighted } \\
\text { Mean }\end{array}$ & $\begin{array}{l}\text { Highest } \\
\text { C.B. }\end{array}$ & $\begin{array}{l}\text { Lowest } \\
\text { C.B. }\end{array}$ & $\begin{array}{c}\text { Total } \\
\text { Deaths }\end{array}$ & $\begin{array}{l}\% \text { of } \\
\text { IM }\end{array}$ & $\begin{array}{l}\% \text { of } \\
\text { IM+ } \\
\text { STI }\end{array}$ \\
\hline $\begin{array}{l}\text { Infant mortality } \\
\text { Stillbirths }\end{array}$ & $\begin{array}{l}66 \cdot 6 \\
44 \cdot 5\end{array}$ & $\begin{array}{l}70 \cdot 4 \\
43 \cdot 6\end{array}$ & $\begin{array}{l}97 \cdot 6 \\
69 \cdot 7\end{array}$ & $\begin{array}{l}41 \cdot 9 \\
32 \cdot 7\end{array}$ & $\begin{array}{l}164,414 \\
101,859\end{array}$ & $\begin{array}{r}100 \cdot 0 \\
62 \cdot 0\end{array}$ & $\begin{array}{l}61 \cdot 7 \\
38 \cdot 3\end{array}$ \\
\hline $\begin{array}{l}\text { By cause: } \\
\text { Congenital causes } \\
\text { Infectious diseases } \\
\text { Bronchitis and }\end{array}$ & $\begin{array}{r}32 \cdot 9 \\
3 \cdot 9\end{array}$ & $\begin{array}{r}33 \cdot 1 \\
4 \cdot 7\end{array}$ & $\begin{array}{r}47 \cdot 0 \\
8 \cdot 2\end{array}$ & $\begin{array}{r}.22 \cdot 9 \\
1 \cdot 2\end{array}$ & $\begin{array}{l}77,255 \\
10,880\end{array}$ & $\begin{array}{r}47 \cdot 0 \\
6 \cdot 6\end{array}$ & $\begin{array}{r}29 \cdot 0 \\
4 \cdot 1\end{array}$ \\
\hline $\begin{array}{l}\text { pneumonia } \\
\text { Diarrhoea } \\
\text { Other causes }\end{array}$ & $\begin{array}{r}14 \cdot 2 \\
5 \cdot 5 \\
10 \cdot 0\end{array}$ & $\begin{array}{r}15 \cdot 4 \\
7 \cdot 0 \\
10 \cdot 2\end{array}$ & $\begin{array}{l}26 \cdot 6 \\
13 \cdot 2 \\
20: 5\end{array}$ & $\begin{array}{l}6 \cdot 0 \\
1 \cdot 1 \\
5 \cdot 9\end{array}$ & $\begin{array}{l}36,084 \\
16,424 \\
23,771\end{array}$ & $\begin{array}{l}21 \cdot 9 \\
10 \cdot 0 \\
14 \cdot 5\end{array}$ & $\begin{array}{r}13 \cdot 6 \\
6 \cdot 2 \\
8 \cdot 9\end{array}$ \\
\hline $\begin{array}{l}\text { By age at death: } \\
\text { 0-1 day } \quad . \\
\text { 1-7 days } \quad . \\
\text { 1-4 weeks } \quad . \\
4 \text { weeks-3 months } \\
\text { 3-6 months } . . \\
\text { 6-9 months } . \\
\text { 9-12 months }\end{array}$ & $\begin{array}{r}10 \cdot 9 \\
12 \cdot 3 \\
9 \cdot 8 \\
10 \cdot 7 \\
9 \cdot 3 \\
7 \cdot 3 \\
6 \cdot 4\end{array}$ & $\begin{array}{r}11 \cdot 1 \\
12 \cdot 0 \\
9 \cdot 8 \\
11 \cdot 5 \\
10 \cdot 5 \\
8 \cdot 2 \\
7 \cdot 2\end{array}$ & $\begin{array}{l}15 \cdot 2 \\
16 \cdot 6 \\
16 \cdot 8 \\
16 \cdot 7 \\
15 \cdot 9 \\
14 \cdot 1 \\
11 \cdot 8\end{array}$ & $\begin{array}{l}7 \cdot 4 \\
7 \cdot 8 \\
4 \cdot 4 \\
4 \cdot 8 \\
4 \cdot 1 \\
2 \cdot 9 \\
2 \cdot 9\end{array}$ & $\begin{array}{l}25,994 \\
27,953 \\
22,941 \\
26,953 \\
24,541 \\
19,211 \\
16,821\end{array}$ & $\begin{array}{l}15 \cdot 8 \\
17 \cdot 0 \\
14 \cdot 0 \\
16 \cdot 4 \\
14 \cdot 9 \\
11 \cdot 7 \\
10 \cdot 2\end{array}$ & $\begin{array}{r}9 \cdot 8 \\
10 \cdot 5 \\
8 \cdot 6 \\
10 \cdot 1 \\
9 \cdot 2 \\
7 \cdot 2 \\
6 \cdot 3\end{array}$ \\
\hline
\end{tabular}

Some figures indicating the distribution of mortality to be accounted for by the regression equations are given in Table IV. The first column shows the mean 
mortality rate obtained by averaging the rates for the individual county boroughs. The next column gives the rate obtained by dividing the aggregate of deaths by the aggregate of births, which has the effect of weighting the contribution of each borough by its total of births. Where the weighted mean is larger than the unweighted, the more populous county boroughs tend to have a higher mortality rate than the smaller places, and vice versa. It will be observed that large population is positively associated with infant mortality, and negatively with stillbirths. Congenital causes and other causes, as well as deaths in the first four weeks, have unweighted and weighted means that are substantially identical; in the other cause

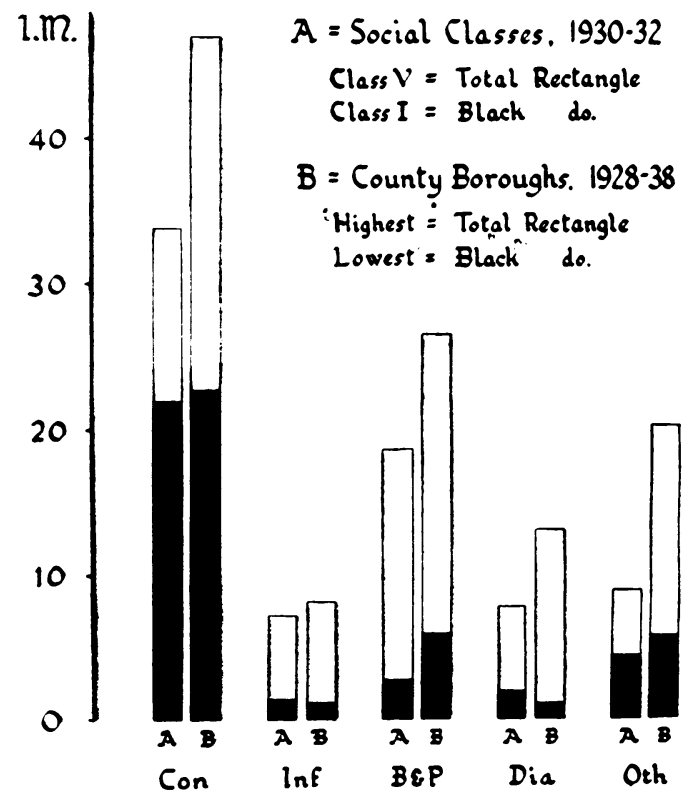

FIG. 6.-Comparison of the range of mortality rates by cause groups in the Registrar-General's social classes and in county boroughs.

groups and in deaths after the first month, high mortality is associated with large population. The table next gives the range of mortality rates for each heading. The ratio of the highest to the lowest for total infant mortality, stillbirths, and congenital causes is just over $2: 1$. For all other cause groups the ratio is much bigger, being about $3 \frac{1}{2}$ for other causes, $4 \frac{1}{2}$ for bronchitis and pneumonia, 7 for infectious diseases, and 12 for diarrhoea. Fig. 6 shows the range of variation among county boroughs for each cause group, in comparison with the difference in 1930-2 between Social Classes I and V. It will be seen that in each case the range in county boroughs is greater, showing that the Registrar-General's analysis of infant deaths by social class by no means expresses the full extent of the contrasts in infant mortality in different sections of the population. Table IV also shows the total number of deaths within each category, and the percentage contribution of 
these deaths to (a) all deaths of live-born babies, and $(b)$ all infant deaths + stillbirths, the total wastage of lives associated with birth and infancy. It will be seen that stillbirths constitute nearly two-fifths of this wastage, neonatal deaths nearly three-tenths, and deaths during the postnatal period nearly one-third. Among these the biggest single cause group is bronchitis and pneumonia.

\section{Indices of Social Conditions}

The five social indices used by Woolf and Waterhouse (1945) are listed in the first paragraph of this paper. Woolf and Waterhouse gave a full description of the criteria and procedure by which this group of five was selected from about thirty indices tried. By the objective test of the magnitude of the coefficient of multiple correlation, it was shown that the percentage of families living more than one person per room, when taken in conjunction with the other social indices, was a measure of overcrowding more closely relevant to infant mortality than percentage of families living more than $1 \frac{1}{2}$ or more than 2 persons per room, than the logarithm of either of these two indices, and than two indices derived from the 1936 statutory Housing Survey. The other indices were similarly selected from among the available measures of unemployment, poverty, and employment of women. Woolf and Waterhouse also tried out indices of other kinds. For reasons stated in their paper, they were unable to obtain a satisfactory measure for a number of other presumably relevant social conditions, including size of built-up area, density of population on the site, and efficiency of infant welfare services. They also tried out and decided not to include a measure of size of family, but for reasons other than the manifest imperfections of the index. They stated:

\footnotetext{
"As a rough index of the relative number of children per family we used G, the gross reproduction rate for county boroughs in 1931, as calculated by Charles (1938). Unlike the indices just considered, this social variable in conjunction with $H, U, P, F$ and $L$ did give appreciable extra covariance. . . . Nevertheless, we decided to omit this index. . . . We have evidence that the relation between $G$ and IM is not simple and straightforward. With some causes of death, $G$ gives positive regression coefficients, and negative ones with others. We hope to deal with the $G$ effect in a subsequent communication."
}

In fact, the inclusion of $G$ in the equations was postponed until the analysis of infant mortality by cause groups and age periods, which is the function of this paper. Since the work of Woolf and Waterhouse, other possible indices have been further investigated, resulting in the computation of a fairly satisfactory measure of density of population on the site. In this paper, therefore, seven indices are used, consisting of the five employed by Woolf and Waterhouse and two new ones which will now be briefly described.

Size of Family.-The measure used is G, the gross reproduction rate in 1931, as calculated by Charles (1938) from Census data. The gross reproduction rate is the computed average number of girl babies produced by a woman during the whole of her reproductive period. It is not a perfect measure of size of family, for several reasons. In the first place, the calculations are made by postulating equal numbers of women in each reproductive age-group, so that if the female 
populations in two places have different age-compositions the index will tend to misrepresent the relative mean family sizes. Secondly, the index takes no account of infant and child mortality, so that in places with a high death rate the family size will be exaggerated. Thirdly, the index refers only to current births, whereas the existing families were produced over a period during which the reproduction rate may have been different. Lastly, and probably most important, the index is highly sensitive to the proportion of women who are married. Two places might have exactly the same average family size, but if one has a higher ratio of married to single women, it will have a correspondingly bigger gross reproduction rate. This distorting effect is especially likely to be important in well-to-do places and holiday resorts, where there is a concentration of unmarried domestic servants, and in centres of mining and heavy industry, from which girls migrate to take up domestic work. The former will give an unduly low index, and the latter one that is too high. Since the well-to-do places have low infant and child mortalities, the last two effects will tend to cancel out. These criticisms, except possibly the last, do not apply to the gross reproduction rate when used for its primary purpose, as an indicator of population trends in the future, but only to its use as a measure of the mean size of actually existing families at the time of computation. Nevertheless, the gross reproduction rate is probably the best available index of relative family size, and, by the objective test of the amount of variance it is able to explain, it seems to be highly relevant in accounting for the observed distribution of infant mortality and stillbirth rates.

Density of Population.-Woolf and Waterhouse wished to include an index of crowding on the site, but were unable to do so. In their own words:

" Successive reports from the Registrar-General's office have been pointing to the positive relation between mortality and density of population ever since the time of William Farr. But the construction of an accurate index is a formidable task. The usual criterion-persons per acre-cannot be applied to big areas like county boroughs. Some cities-Leeds and Birmingham, for example-have extended their boundaries to include undeveloped land to be used for future housing schemes. Their figures for persons per acre would be fictitiously low. In other cases the value of the index will depend on exactly where the borough boundary runs in relation to open spaces or factory areas on the outskirts. We tried out a persons-peracre index. It gave an obviously distorted picture of comparative densities of population, and its correlation with infant mortality was negligible."

The ideal index would be constructed as follows. With the location of each individual as centre, draw a circle with an area of one acre, and count the number of people it encloses. Add all these figures and divide by the number in the population. This would give the average number of people within one acre's surround of any individual, and so be a true measure of crowding as it is likely to influence spread of infection or of other effects of closeness of packing on infant mortality. The calculation of such an index is obviously entirely impracticable. But it is possible to obtain an approximation to it, by the method illustrated in Table V. An imaginary municipality is divided into two wards, A and B, each of 100 acres, with the populations shown in the table. The usual method of calculating density is to divide the total population by the total area, which in this case gives 
a figure of 60 persons per acre. But in Ward A there are three people suffering crowded conditions for every person enjoying comparative spaciousness in Ward B, so the figure of 60 is an underestimate of the crowding when measured as centring

TABLE V

Method of Calculation of Weighted Index of Density of Population

\begin{tabular}{ccc|c|c|c|c}
\hline & & & Acres & Population & Persons per Acre & $\begin{array}{c}\text { Persons per Acre } \\
\times \text { Population }\end{array}$ \\
\hline A & $\ldots$ &. & 100 & 9,000 & 90 & 810,000 \\
& $\ldots$ &. & 100 & 3,000 & 30 & 90,000 \\
& Total &.. & 200 & 12,000 & & 900,000 \\
\hline
\end{tabular}

Persons per acre: unweighted, $\frac{12,000}{200}=60 ; \quad$ weighted, $\frac{900,000}{12,000}=75$.

round each individual. If, however, one is prepared to assume that within each ward the population is evenly distributed, so that each single acre in A contains 90 and each acre in B contains 30 people, one can easily calculate the corrected or weighted index. In Ward A, 9,000 people are each surrounded by 30 . The average density, measured round people, is found by multiplying for each ward the population by the density, and dividing the total of such products by the total population. In the example in Table $\mathrm{V}$, the result is 75 persons per acre, an appreciably higher figure than the unweighted density.

The advantage of the weighted index may be more clearly exhibited by considering an extreme case. Suppose that to the municipality in Table $V$ there is added a third ward, $\mathrm{C}$, of 100 acres, but containing no population at all. The total area now rises to 300 acres, reducing the unweighted density from 60 to 40 . But the weighted density will remain unchanged. If the new ward had, say, one person per acre, it would still depress the unweighted density by almost one-third, while having no appreciable effect on the weighted density. In general, sparsely populated areas are discounted by the weighted index, but exert a disproportionate influence on the unweighted measure. The weighted index is always higher than the unweighted, and the more unevenly the population is distributed the greater the difference between the two indices.

In the example in Table $V$, it was assumed that population was evenly spaced within each ward. If this assumption were untrue, the weighted index would still be an underestimate of the closeness of packing of the population. For example, suppose that in Ward A half the area is populated at a density of 120 and the other half at 60 , giving the average figure of 90 per acre as shown in the table. The unweighted index will of course be unchanged, but the weighted index will be raised from 75 to $82 \cdot 5$. For the successful application of the method shown in Table $V$ 
to actual county boroughs, therefore, it would be necessary to have figures of area and population relating to subdivisions small enough to justify the assumption that density of settlement within each division was substantially constant.

This condition is not very well satisfied by the available data. In the 1931 Census, figures of area and population are given for each county borough by wards and sometimes by other kinds of sub-areas. From these the weighted density in each borough was calculated by the method illustrated in Table V. On the average, the weighted density exceeds the unweighted by about $76 \%$. But for some places, such as East Ham, the difference is much less. These are boroughs which are fully built up, and which are fairly homogeneous in density of occupation in the different wards. In other cases the weighting process increases the density several fold. Examples are Barrow, where the figure is raised from 6 to 26; Leeds, from 13 to 38; and Brighton, from 12 to 66 . These are boroughs containing undeveloped land, or localized areas of factories, docks, or shipyards. The correlation between weighted and unweighted density is about $0 \cdot 84$. The weighted index, as shown later, gives appreciable correlation and regression coefficients with the various components of infant mortality. Although it is probably only a rough approximation to the true average density per person as defined above, it is nevertheless a relevant index in respect of infant death rates. The weighted index of persons per acre is denoted by the symbol $D$.

TABLE VI

First Order Correlations among Social Indices

\begin{tabular}{|c|c|c|c|c|c|c|c|}
\hline & & $\mathbf{U}$ & $\mathbf{P}$ & $F$ & $\mathbf{L}$ & G & $\dot{D}$ \\
\hline $\begin{array}{l}\mathbf{H} \\
\mathbf{U} \\
\mathbf{P} \\
\mathbf{F} \\
\mathbf{L} \\
\mathbf{G}\end{array}$ & $\begin{array}{l}. . \\
. . \\
\ldots \\
\ldots \\
.\end{array}$ & $\begin{array}{c}0.6378 \\
= \\
= \\
=\end{array}$ & $\begin{array}{c}0.6870 \\
0.5353 \\
= \\
= \\
=\end{array}$ & $\begin{array}{c}-0.0218 \\
-0.0985 \\
0.0768 \\
- \\
-\end{array}$ & $\begin{array}{c}0.5348 \\
0.4743 \\
0 \cdot 5015 \\
0 \cdot 2681 \\
=\end{array}$ & $\begin{array}{r}0.7256 \\
0.5496 \\
0.6987 \\
-0.2404 \\
0.3120 \\
-\end{array}$ & $\begin{array}{r}0.4311 \\
0.2657 \\
0.2836 \\
-0.0628 \\
0.1447 \\
0.4244\end{array}$ \\
\hline
\end{tabular}

First order correlations among the social indices are set out in Table VI. One of the new indices, $G$, shows quite a high correlation with $H$. Size of family is strongly associated with overcrowding in the house. The correlations with $P$ and $U$, though lower, are also considerable. Poverty and unemployment tend to be highest in boroughs where family sizes are above the average. The correlation with $F$ is negative, and rather small. On the whole, industrial employment of women is associated with small numbers of children. The other new index, D, gives unexpectedly low correlations with $\mathbf{H}$ and $\mathbf{G}$. Density on the site is not the same social phenomenon as overcrowding in the house or large family size. The small correlations between $D$ and the other variables indicate that its inclusion in 
the regression equations may add appreciably to the amount of variance accounted for.

TABLE VII

First Order Correlations between Mortality Rates and Social Indices

\begin{tabular}{|c|c|c|c|c|c|c|c|c|c|}
\hline & & & $\mathbf{H}$ & $\mathbf{U}$ & $\mathbf{P}$ & $F$ & L & $\mathbf{G}$ & D \\
\hline $\begin{array}{l}\text { IM } \\
\text { STI }\end{array}$ & $\begin{array}{l}. \\
\ldots\end{array}$ & $\begin{array}{l}. . \\
. .\end{array}$ & $\begin{array}{l}0.7353 \\
0.2004\end{array}$ & $\begin{array}{l}0.6651 \\
0.4734\end{array}$ & $\begin{array}{l}0.6686 \\
0.2898\end{array}$ & $\begin{array}{l}0.3428 \\
0.4221\end{array}$ & $\begin{array}{l}0.6634 \\
0.4000\end{array}$ & $\begin{array}{r}0.5655 \\
-0.0966\end{array}$ & $\begin{array}{r}0.3394 \\
-0.1981\end{array}$ \\
\hline $\begin{array}{l}\text { CON } \\
\text { INF } \\
\text { B \& P } \\
\text { DIA } \\
\text { OTH }\end{array}$ & $\begin{array}{l}. \\
\therefore \\
\cdots \\
\ldots\end{array}$ & \begin{tabular}{l|}
. \\
. \\
. \\
.
\end{tabular} & $\begin{array}{l}0.4650 \\
0.6438 \\
0.7566 \\
0.6101 \\
0.5171\end{array}$ & $\begin{array}{l}0.4691 \\
0.4832 \\
0.6659 \\
0.3554 \\
0.6738\end{array}$ & $\begin{array}{l}0.4821 \\
0.5901 \\
0.6988 \\
0.4303 \\
0.4693\end{array}$ & $\begin{array}{l}0 \cdot 4875 \\
0 \cdot 1956 \\
0 \cdot 2299 \\
0 \cdot 1812 \\
0 \cdot 1248\end{array}$ & $\begin{array}{l}0.6061 \\
0.4493 \\
0.5587 \\
0.3841 \\
0.5896\end{array}$ & $\begin{array}{l}0.2436 \\
0.5623 \\
0.6701 \\
0.5529 \\
0.3273\end{array}$ & $\begin{array}{r}-0.0134 \\
0.5265 \\
0.3912 \\
0.5748 \\
0.1688\end{array}$ \\
\hline $\begin{array}{l}\text { DAY } \\
\text { WK } \\
\text { MON } \\
1 Q \\
2 Q \\
3 Q \\
\text { 3Q } \\
4 \text { Q }\end{array}$ & $\begin{array}{l}. \\
\ldots \\
. . \\
. . \\
.\end{array}$ &. & \begin{tabular}{l|}
0.2323 \\
0.3369 \\
0.6806 \\
0.6477 \\
0.7465 \\
0.7447 \\
0.7626
\end{tabular} & $\begin{array}{l}0.1634 \\
0.4544 \\
0.6298 \\
0.5818 \\
0.6624 \\
0.6215 \\
0.6171\end{array}$ & $\begin{array}{l}0.1508 \\
0.3632 \\
0.6116 \\
0.6167 \\
0.6583 \\
0.6329 \\
0.7206\end{array}$ & $\begin{array}{l}0 \cdot 4265 \\
0 \cdot 4371 \\
0 \cdot 2846 \\
0 \cdot 2613 \\
0 \cdot 1621 \\
0 \cdot 2794 \\
0 \cdot 2081\end{array}$ & $\begin{array}{l}0 \cdot 3453 \\
0 \cdot 6521 \\
0 \cdot 6586 \\
0 \cdot 5404 \\
0 \cdot 5547 \\
0 \cdot 5431 \\
0 \cdot 5007\end{array}$ & $\begin{array}{r}-0.0167 \\
0.0688 \\
0.4750 \\
0.5560 \\
0.6885 \\
0.6442 \\
0.6947\end{array}$ & $\begin{array}{r}-0.1174 \\
-0.1940 \\
0.1899 \\
0.4325 \\
0.5375 \\
0.4812 \\
0.4536\end{array}$ \\
\hline
\end{tabular}

Table VII shows the first order correlations between the social indices and the various mortality rates. These will be commented on later.

\section{Methods of Computation}

Each variable was coded in a series of whole numbers, giving a range of approximately 30 steps. The regression matrix was made up of sums of squares of deviations from the mean, and of products of the deviations taken in pairs, among the independent variables. The inverse matrix was obtained by the Doolittle method, solving for seven columns with values $1,0,0,0,0,0,0 ; 0,1,0,0,0,0,0$; and so on. To avoid several zeros after the decimal point in the inverse matrix, the regression matrix was divided throughout by an appropriate power of 10. From this one inverse matrix it is possible to obtain the coefficients of multiple regression on the seven independent variables for any mortality rate, the only extra information required being the sums of products of deviations from the mean for the mortality rate in question with each of the seven social indices.

In checking the various calculations, use was made of some algebraic identities that are easily proved, though they do not seem to have been stated before. Let $A$ and $X$ be two correlated variables, and $a$ and $x$ their respective deviations from the mean. Let $\mathrm{A}$ be partitioned in any manner into sub-variables $\mathrm{P}, \mathrm{Q}, \mathrm{R}$. . . , such that for any given value of $X$ the sum of the sub-variables $P, Q, R \ldots$. is 
the corresponding value of $A$. Let $p, q, r \ldots$ be the deviations of $P, Q, R \ldots$ from their respective means. Then

$$
\Sigma \mathrm{ax}=\Sigma \mathrm{px}+\Sigma \mathrm{qx}+\Sigma \mathrm{rx}+\ldots \ldots \ldots
$$

If $X$ is treated as the independent variable, then the regression coefficient of $A$ on $X$ is always equal to the sum of the regression coefficients on $X$ of the sub-variables $P, Q, R$. . . If there are any number of independent variables $X, Y, Z$. . ., on which multiple regressions are computed for the dependent variable $A$ and the sub-variables $\mathbf{P}, \mathbf{Q}, \mathbf{R}$. . ., then the sum of the regression coefficients of these sub-variables on any of the independent variables must equal the regression coefficient of $A$ on the same independent variable. To put it briefly, covariances and regression coefficients are additive.

Besides the individual regression coefficients, two other figures are required to complete the calculations of a multiple regression equation. One of these is the proportion of variance accounted for by the equation which American authors call the "coefficient of determination", but which Woolf and Waterhouse (1945) preferred to call the "explanation". This figure is of course the square of $\mathbf{R}$, the coefficient of multiple correlation, and is easily calculated in the course of solving the regression equations.

The other parameter is the regression constant, $\mathrm{K}$, giving the computed value of the dependent variable when each of the independent variables is at some chosen origin. Woolf and Waterhouse fixed the valtaes of their social indices for the calculation of $\mathrm{K}$ so as to make this parameter give an estimate of the mortality rate to be expected if adverse social conditions could have been eliminated. They put $\mathrm{H}, \mathrm{U}, \mathrm{P}$, and $\mathrm{F}$ at zero, so postulating an ideal population without overcrowding, unemployment, low-paid occupations, or industrial employment of women. But obviously it would have been absurd to put the value of $L$, the latitude, at zero also. This would have postulated an English county borough at the Equator. Since infant mortality increases with increasing latitude, they put their origin in the extreme south of England, at latitude $50^{\circ} 30^{\prime}$. It would be equally absurd with the two new social indices, $G$ and $D$, to put the origin at zero. The value of $K$ would then give the computed mortality rates for a population where the women bore no children and which lived at a density of no persons per acre. It is necessary to fix a reasonable origin for these two new indices, at the sort of level to be expected in a well-to-do community. The three county boroughs with the lowest values of gross reproduction rate in 1931 were: Bournemouth, 0.549; Southport, 0.594; Blackpool, $0 \cdot 600$. These are all seaside resorts, where the reproduction rate would have been artificially depressed by an excess of unmarried female domestic and catering workers. A reasonable origin for $G$, as representing conditions in the wealthiest towns, would therefore be somewhere about $0 \cdot 6$, and this is the origin used in this paper in the calculations of $K$. For D, the weighted density, the arbitrary figure chosen is 20 persons per acre, as representing the approximate level aimed at in good planned housing. The value of $\mathrm{K}$ in each of the equations 
therefore gives the mortality rate to be expected, if the equation is a true description of the facts, in an ideal population with:

No families living more than one person per room.

No men unemployed.

No men in low-paid occupations.

No women employed in industry.

$A$ latitude of $50^{\circ} 30^{\prime}$-that of the extreme south of England.

A gross reproduction rate of $0 \cdot 6$.

A weighted density of 20 persons per acre.

TABLE VIII

REgRESSION EQUATIONS

\begin{tabular}{|c|c|c|}
\hline IM .. & $\because$ & $\begin{array}{l}7 \mathrm{H}+0.441 \mathrm{U}+0.153 \mathrm{P}+0.407 \mathrm{~F}+2 \cdot 14 \mathrm{~L}+11.98 \mathrm{G}+0.044 \mathrm{D} \\
\mathrm{H}+0.535 \mathrm{U}+0.351 \mathrm{P}+0.195 \mathrm{~F}+0.14 \mathrm{~L}-22.43 \mathrm{G}-0.113 \mathrm{D}\end{array}$ \\
\hline & & \\
\hline $\mathbf{P}$ & 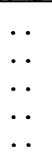 & $\begin{array}{l}=19.807+0.102 \mathrm{H}+0.153 \mathrm{U}+0.090 \mathrm{P}+0.183 \mathrm{~F}+0.98 \mathrm{~L}-0.36 \mathrm{G}-0.065 \mathrm{D} \\
=0.211+0.029 \mathrm{H}+0.015 \mathrm{U}+0.030 \mathrm{P}+0.029 \mathrm{~F}+0.08 \mathrm{~L}+1.33 \mathrm{G}+0.028 \mathrm{D} \\
=0.031+0.118 \mathrm{H}+0.147 \mathrm{U}+0.073 \mathrm{P}+0.127 \mathrm{~F}+0.26 \mathrm{~L}+7.83 \mathrm{G}+0.021 \mathrm{D} \\
=2.002+0.083 \mathrm{H}-0.018 \mathrm{U}-0.072 \mathrm{P}+0.064 \mathrm{~F}+0.23 \mathrm{~L}+5.55 \mathrm{G}+0.060 \mathrm{D} \\
=4.743+0.023 \mathrm{H}+0.136 \mathrm{U}+0.034 \mathrm{P}+0.011 \mathrm{~F}+0.55 \mathrm{~L}-2.16 \mathrm{G}-0.001 \mathrm{D}\end{array}$ \\
\hline &. & $=26.794+0.355 \mathrm{H}+0.433 \mathrm{U}+0.155 \mathrm{P}+0.414 \mathrm{~F}+2.10 \mathrm{~L}+$ \\
\hline $\begin{array}{l}\text { WK } \\
\text { MON } \\
1 Q \ldots \\
2 Q \ldots \\
3 Q \ldots \\
4 Q \ldots\end{array}$ & $\begin{array}{l}\ldots \\
\cdots \\
\cdots \\
\cdots \\
\cdots \\
\cdots \\
\cdots\end{array}$ & $\begin{array}{l}=9.068+0.066 \mathrm{H}+0 \\
=7.452+0.030 \mathrm{H}+0 \\
=3.376+0.076 \mathrm{H}+0 \\
=3.975+0.030 \mathrm{H}+0 \\
=2.091+0.043 \mathrm{H}+0 \\
=1.343+0.063 \mathrm{H}+0 \\
=0.266+0.057 \mathrm{H}+0\end{array}$ \\
\hline & . & $=27 \cdot 039+0.365 \mathrm{H}+0.436 \mathrm{U}+0 \cdot 145 \mathrm{P}+0.409 \mathrm{~F}+2 \cdot 10 \mathrm{~L}+12 \cdot 14 \mathrm{G}+0.04$ \\
\hline & & \\
\hline
\end{tabular}

The value of $\mathrm{K}$ in this paper may be expected not to correspond exactly with that given by Woolf and Waterhouse, for two reasons. First, the mortality rates used here are based on pooled births and deaths over the eleven years, and so give slightly more weight to the years of high mortality, when births were also higher. This will tend to increase the value of $\mathbf{K}$ calculated on the new basis. Secondly, the value of $\mathrm{K}$ will vary with the exact levels arbitrarily chosen as the origins for $G$ and $D$. If, as is in fact the case, the rates of 0.6 for $G$ and 20 persons per acre for $\mathrm{D}$ are higher than those actually obtaining among the best-off section of the population, the value of $\mathrm{K}$ will be increased on this score also. There is another point to be noted about the values of $\mathrm{K}$ in the various equations. For reasons stated by Woolf and Waterhouse, all the county boroughs were given equal weight in the computations, irrespective of their populations. The values of $\mathrm{K}$ calculated from these unweighted rates are those given in Table VIII. There is an alternative way of calculating $\mathrm{K}$, taking some account of relative populations sizes, and the figures so obtained give what is in some respects a truer estimate of mortality rates 
in the better-off sections of the population of county boroughs. These values are set out and discussed in a later section.

\section{The Regression Equations}

Table VIII shows the regression equations for the various mortality rates for 82 out of the 83 county boroughs in England and Wales over the eleven years 1928 to 1938. Bootle had to be omitted because of lack of unemployment data. The table is arranged in four sections. The first gives the equations for total infant mortality (IM) and for stillbirths (STI), and the sum, constituting the equation for the total wastage of life during birth and infancy. Next comes infant mortality, divided into the five cause groups, with a check total. Then the seven periods of infancy are given, again with a check total. Finally the equation for the neonatal period - the first four weeks of life (NEO)-is obtained by summing the three equations for DAY, WK, and MON, and compared with the expression for the postnatal period, the rest of the year of infancy (POST), which is the sum of the equations for $1 \mathrm{Q}, 2 \mathrm{Q}, 3 \mathrm{Q}$, and $4 \mathrm{Q}$. The two check totals should correspond with the equation for infant mortality at the top of the table, and do so fairly well. The small diserepancies arise from rounding-off errors involved in coding into whole numbers, computation of the coefficients, and decoding. It would have been possible, by forcing the figures so as to make all intermediate totals tally, to get the check totals to correspond exactly; but as this would have involved some distortion of the individual equations, it was not considered desirable.

TABLE IX

Significances of Equations

\begin{tabular}{|c|c|c|c|c|c|c|}
\hline \multicolumn{2}{|c|}{ Equation } & $\mathbf{R}$ & $\mathbf{E}=\mathbf{R}^{2}$ & $1-E$ & F & $\begin{array}{l}\text { S.E. of } \\
\text { Estimate }\end{array}$ \\
\hline $\begin{array}{l}\text { IM } \\
\text { STI }\end{array}$ & $\begin{array}{l}. \\
\therefore\end{array}$ & $\begin{array}{l}0.8960 \\
0.8079\end{array}$ & $\begin{array}{l}0.8027 \\
0.6527\end{array}$ & $\begin{array}{l}0 \cdot 1973 \\
0 \cdot 3473\end{array}$ & $\begin{array}{l}43 \cdot 0 \\
19 \cdot 9\end{array}$ & $\begin{array}{l}6 \cdot 03 \\
4 \cdot 51\end{array}$ \\
\hline $\begin{array}{l}\text { CON } \\
\text { INF } \\
\text { B \& P } \\
\text { DIA } \\
\text { OTH }\end{array}$ & $\begin{array}{l}. \\
. \\
\ldots \\
\ldots \\
.\end{array}$ & $\begin{array}{l}0.7920 \\
0 \cdot 7707 \\
0 \cdot 8781 \\
0 \cdot 7664 \\
0 \cdot 7526\end{array}$ & $\begin{array}{l}0.6272 \\
0 \cdot 5940 \\
0 \cdot 7711 \\
0 \cdot 5874 \\
0 \cdot 5664\end{array}$ & $\begin{array}{l}0 \cdot 3728 \\
0 \cdot 4060 \\
0 \cdot 2289 \\
0 \cdot 4126 \\
0 \cdot 4336\end{array}$ & $\begin{array}{l}17 \cdot 8 \\
15 \cdot 5 \\
35 \cdot 6 \\
15 \cdot 0 \\
13 \cdot 8\end{array}$ & $\begin{array}{l}3 \cdot 14 \\
0 \cdot 93 \\
2 \cdot 35 \\
1 \cdot 75 \\
1 \cdot 56\end{array}$ \\
\hline $\begin{array}{l}\text { DAY } \\
\text { WK } \\
\text { MON } \\
1 Q \\
2 Q \\
3 Q \\
4 Q\end{array}$ & $\begin{array}{l}\ldots \\
\cdots \\
\cdots \\
\cdots \\
\cdots \\
\cdots\end{array}$ & $\begin{array}{l}0.5608 \\
0.8233 \\
0.8301 \\
0.8002 \\
0.8834 \\
0.8809 \\
0.8763\end{array}$ & $\begin{array}{l}0.3145 \\
0 \cdot 6778 \\
0 \cdot 6891 \\
0.6403 \\
0.7804 \\
0.7759 \\
0.7679\end{array}$ & $\begin{array}{l}0 \cdot 6855 \\
0 \cdot 3222 \\
0 \cdot 3109 \\
0 \cdot 3597 \\
0 \cdot 2196 \\
0 \cdot 2241 \\
0 \cdot 2321\end{array}$ & $\begin{array}{r}4 \cdot 8 \\
22 \cdot 2 \\
23 \cdot 4 \\
18 \cdot 8 \\
37 \cdot 6 \\
36 \cdot 6 \\
35 \cdot 0\end{array}$ & $\begin{array}{l}1.45 \\
1.27 \\
1.27 \\
1.53 \\
1.35 \\
1.13 \\
1.05\end{array}$ \\
\hline
\end{tabular}

$0.1 \%$ point for $F=3.9$ 
Each regression coefficient gives the change in the mortality rate to be expected for an increase of one unit in the social index in question. The coefficient is therefore inversely proportional to the unit of measurement, so the relative sizes of the coefficients for the different social indices are no guide to their relative importance in relation to infant mortality. If, for example, latitude had been measured in minutes instead of degrees, its regression coefficients would have been one-sixtieth of those shown in the table. $G$ is another social variable with a very small numerical range of variation, the highest value being 1.43 and the lowest $0 \cdot 55$. Its regression coefficients are accordingly quite large figures. Before any aetiological conclusions can be drawn from the equations, the influences of the various social agencies must be exhibited on a comparable basis. This is done in the next section.

Tests of the statistical significance of the various equations, involving the conventional assumptions about random sampling from a normally distributed universe, are set out in Table IX. For each equation there is shown:

The coefficient of multiple correlation, denoted by $\mathbf{R}$.

The explanation, or proportion of total variance accounted for by the equation. This is of course equal to $\mathbf{R}^{2}$, and is denoted by $\mathrm{E}$.

The non-explanation, or residual variance, which equals $1-\mathrm{E}$.

The value of Snedecor's F calculated for the appropriate number of degrees of freedom, according to the formula

$$
F=\frac{74 E}{7(1-E)}
$$

It is clear from the table that the level of explanation is high. With one exception, all values of $R$ are above $0 \cdot 75$, and of $E$ above $0 \cdot 56$. The exception is mortality during the first 24 hours, which would be expected to have a large error variance owing to uncertainty of timing of births and deaths. But even this equation has an $F$ of 4.8 as compared with the $0.1 \%$ point of 3.9 , which means that, on the conventional assumptions, the odds are much more than 1,000 to 1 against the regression arising from chance fluctuations. For the other equations the $\mathrm{F}$ values are much higher, rising to 43 for total infant mortality. The equations as a whole may therefore be regarded as highly significant. The reliability of the individual regression coefficients, and the extent to which the equations can be regarded as accounting for all observed mortality differences, will be discussed in a later section.

The last column of Table IX gives the standard error of estimate for each equation. If the mortality rates for the individual county boroughs are calculated from the equations, the differences between the computed and the actual figures will be less than the value shown in approximately two-thirds of the cases. The equations enable total infant mortality rate to be estimated for any county borough with a standard error of about 6 units, and stillbirth rate within $\pm 4 \cdot 5$. For the seven periods of infancy the standard error varies between 1.05 and 1.53. The 
various cause groups have standard errors of estimate ranging from 0.93 for infectious diseases, whose mean rate is the smallest at $3 \cdot 85$, to $3 \cdot 14$ for congenital causes, whose mean rate is the highest at $19 \cdot 81$.

TABLE $\mathbf{X}$

Bipmingham, 1928-38: Stillbirths and Infant Deaths observed and Calculated from REGRESSION EQUATIONS

\begin{tabular}{|c|c|c|c|c|c|c|c|c|c|}
\hline & & & & \multicolumn{3}{|c|}{ Rates } & \multicolumn{3}{|c|}{ Deaths } \\
\hline . & & & & IM & STI & Total & IM & STI & Total \\
\hline $\begin{array}{ll}\text { Unexplained } \\
\text { H } & 25 \cdot 1 \% \\
\text { U } & 11 \cdot 2 \% \\
\text { P } & 32 \cdot 3 \% \\
\text { F } & 23 \cdot 9 \% \\
\text { L } & 52 \cdot 2^{\circ} \\
\text { G } & 0 \cdot 972 \\
\text { D } & 41 \cdot 1\end{array}$ & $\begin{array}{l}\ldots \\
\cdots \\
\cdots \\
\cdots \\
\cdots \\
\cdots\end{array}$ & $\begin{array}{l}\ldots \\
\cdots \\
\cdots \\
\cdots \\
\cdots \\
\cdots \\
\ldots\end{array}$ & \begin{tabular}{l|}
. \\
$\cdots$ \\
$\cdots$ \\
$\cdots$ \\
$\cdots$ \\
$\cdots$ \\
$\cdots$
\end{tabular} & $\begin{array}{r}26 \cdot 81 \\
8 \cdot 97 \\
4 \cdot 93 \\
4 \cdot 94 \\
9 \cdot 73 \\
4 \cdot 28 \\
4 \cdot 45 \\
0 \cdot 92\end{array}$ & $\begin{array}{r}25 \cdot 66 \\
1 \cdot 46 \\
5 \cdot 99 \\
11 \cdot 32 \\
4 \cdot 65 \\
0 \cdot 28 \\
-8 \cdot 34 \\
-2 \cdot 38\end{array}$ & $\begin{array}{r}52 \cdot 47 \\
10.43 \\
10.92 \\
16 \cdot 26 \\
14 \cdot 38 \\
4.56 \\
-3.89 \\
-1 \cdot 46\end{array}$ & $\begin{array}{r}4,894 \\
1,638 \\
900 \\
902 \\
1,776 \\
781 \\
813 \\
168\end{array}$ & $\begin{array}{r}4,684 \\
267 \\
1,094 \\
2,067 \\
849 \\
51 \\
-1,523 \\
-435\end{array}$ & $\begin{array}{r}9,578 \\
1,905 \\
1,994 \\
2,969 \\
2,625 \\
832 \\
-710 \\
-267\end{array}$ \\
\hline \multicolumn{2}{|c|}{$\begin{array}{l}\text { Total calculated } \\
\text { Observed } \quad .\end{array}$} & . & $\begin{array}{l}. . \\
. .\end{array}$ & $\begin{array}{l}65 \cdot 03 \\
65 \cdot 83\end{array}$ & $\begin{array}{l}38 \cdot 64 \\
38 \cdot 76\end{array}$ & $\begin{array}{l}103 \cdot 67 \\
104 \cdot 59\end{array}$ & $\begin{array}{l}11,872 \\
12,018\end{array}$ & $\begin{array}{l}7,054 \\
7,076\end{array}$ & $\begin{array}{l}18,926 \\
19,094\end{array}$ \\
\hline \multicolumn{2}{|c|}{ Excess observed } & .. & .. & 0.80 & $0 \cdot 12$ & 0.92 & 146 & 22 & 168 \\
\hline & & & & \multicolumn{6}{|c|}{ Rates } \\
\hline & & & & \multicolumn{2}{|c|}{ Observed } & \multicolumn{2}{|c|}{ Calculated } & \multicolumn{2}{|c|}{ Excess Observed } \\
\hline $\begin{array}{l}\text { CON .. } \\
\text { INF } \\
\text { B \& P } \\
\text { DIA .. } \\
\text { OTH .. }\end{array}$ & $\begin{array}{l}. \\
\cdots \\
\cdots \\
\cdots \\
.\end{array}$ & $\begin{array}{l}. \\
. \\
\cdots \\
.\end{array}$ & $\begin{array}{l}. . \\
. \\
. \\
.\end{array}$ & \multicolumn{2}{|c|}{$\begin{array}{r}32 \cdot 28 \\
5 \cdot 00 \\
12 \cdot 03 \\
7 \cdot 73 \\
8 \cdot 79\end{array}$} & \multicolumn{2}{|c|}{$\begin{array}{r}31 \cdot 81 \\
4 \cdot 03 \\
13 \cdot 93 \\
6 \cdot 87 \\
8 \cdot 47\end{array}$} & \multicolumn{2}{|c|}{$\begin{array}{r}0.47 \\
0.97 \\
-1.90 \\
0.86 \\
0.32\end{array}$} \\
\hline 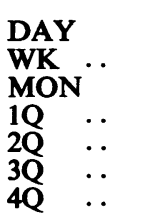 & $\begin{array}{l}\ldots \\
\ddot{.} \\
\ddot{.} \\
\cdots \\
\cdots\end{array}$ & $\begin{array}{l}. \\
. \\
. \\
. \\
. \\
.\end{array}$ & \begin{tabular}{l|}
. \\
. \\
. \\
. \\
. \\
. \\
..
\end{tabular} & \multicolumn{2}{|c|}{$\begin{array}{r}12 \cdot 72 \\
10 \cdot 51 \\
7 \cdot 61 \\
10 \cdot 47 \\
9 \cdot 98 \\
8 \cdot 01 \\
6 \cdot 53\end{array}$} & \multicolumn{2}{|c|}{$\begin{array}{r}10 \cdot 92 \\
11 \cdot 16 \\
9 \cdot 04 \\
10 \cdot 66 \\
9 \cdot 34 \\
7 \cdot 58 \\
6 \cdot 42\end{array}$} & \multicolumn{2}{|c|}{$\begin{array}{r}1.80 \\
-0.65 \\
-1.43 \\
-0.19 \\
0.64 \\
0.43 \\
0.11\end{array}$} \\
\hline NEO . . & . & . & . & \multicolumn{2}{|c|}{$30 \cdot 84$} & \multicolumn{2}{|c|}{$31 \cdot 12$} & \multicolumn{2}{|c|}{$-0 \cdot 28$} \\
\hline POST & .. & . & & \multicolumn{2}{|c|}{$34 \cdot 99$} & \multicolumn{2}{|c|}{$34 \cdot 00$} & \multicolumn{2}{|r|}{0.99} \\
\hline
\end{tabular}

An example of how the equations may be applied to analysing the mortality in an individual county borough is shown in Table $X$, for the largest borough, 
Birmingham. The top part of the table shows the detailed calculation of the expected infant mortality and stillbirths, expressed both as rates and as numbers of deaths, from the values of the seven social indices. As might be expected from its large population and consequently low sampling variance, Birmingham gives closer agreement between calculated and observed deaths than the last column of Table IX might lead one to expect. Infant mortality agrees to within 146 deaths, and stillbirths to within 22 deaths. Similar calculations were made for the deathsby-cause groups and by periods of infancy, and the results are sumntarized at the bottom of the table. In 3 cases out of 12 the difference between observed and calculated rate exceeds the standard error of estimate.

Similar computations performed for other county boroughs indicate that on the whole the larger the place the closer the concordance between expected and observed mortality rates. It is fair to claim that the equations are of quite high efficiency as a means of accounting for infant deaths from a knowledge of the measures of social conditions.

\section{Social Aetiology of Stillbirths and Infant Deaths}

A set of calculations similar to those for Birmingham in Table $\mathrm{X}$ can be made for the country as a whole by substituting in the various equations the mean value of each social index among county boroughs. There is, of course, no question here of finding any difference between calculated and observed rates, since the value of $\mathrm{K}$ is fixed by equating these two rates when the independent variables are all at their means. The object of such computations for the aggregate of county boroughs would be to obtain estimates of the amount of mortality associated with each social index. This procedure is justified only in so far as the individual regression coefficients, as distinct from the equations as a whole, can be regarded as "significant". The discussion of this point is best deferred until after the presentation of the results. For the moment the regression coefficients will be provisionally regarded as reliable measures of the relative influence of the various social agencies on infant deaths.

The results of the computations are set out in Table XI. For each equation there is shown, first, the mean rate for the type of mortality specified, then the $\mathrm{K}$ figure representing the expected rate among the "better-off" population as defined above, then the increment or decrement in mortality associated with each social variable for the average county borough as compared with the baseline population used for calculating $\mathrm{K}$, and finally the total amount of mortality "explained" by the equation, which is of course the mean minus $\mathrm{K}$.

Looking first at the columns headed "Mean ", " $K$ ", and "Total Explained ", one notices the following features: Approximately three-fifths of the total infant mortality and two-fifths of the stillbirths are associated with the differences in social conditions between the average county borough population and the better-off section. For infant mortality and stillbirths together, just over half the deaths are attributable to the specified social agencies. 
Among the cause groups, almost the whole of the mortality from infectious diseases and from bronchitis and pneumonia is socially conditioned. For diarrhoea more than a third, and for other causes nearly a half, of the average mortality rate are found at the better-off level. For congenital causes, $\mathrm{K}$ is about three-fifths of the mean, just as it is for stillbirths.

TABLE XI

MoRTality Rates associated WITH the Various Social INDices

\begin{tabular}{|c|c|c|c|c|c|c|c|c|c|c|}
\hline & Mean & $\mathbf{K}$ & $\mathbf{H}$ & $\mathbf{U}$ & $\mathbf{P}$ & $\mathbf{F}$ & $\mathbf{L}$ & $\mathbf{G}$ & D & $\begin{array}{l}\text { Total } \\
\text { Expl. }\end{array}$ \\
\hline $\begin{array}{l}\text { IM } \\
\text { STI }\end{array}$ & $\begin{array}{l}66 \cdot 60 \\
44 \cdot 48\end{array}$ & $\begin{array}{l}26 \cdot 81 \\
25 \cdot 66\end{array}$ & $\begin{array}{l}9 \cdot 82 \\
1 \cdot 60\end{array}$ & $\begin{array}{r}8 \cdot 64 \\
10 \cdot 49\end{array}$ & $\begin{array}{r}5 \cdot 46 \\
12 \cdot 52\end{array}$ & $\begin{array}{l}6 \cdot 13 \\
2 \cdot 93\end{array}$ & $\begin{array}{l}5 \cdot 12 \\
0 \cdot 34\end{array}$ & $\begin{array}{r}4 \cdot 02 \\
-7 \cdot 52\end{array}$ & $\begin{array}{r}0.60 \\
-1.54\end{array}$ & $\begin{array}{l}39 \cdot 79 \\
18 \cdot 82\end{array}$ \\
\hline$\underset{\text { STI }}{\mathbf{I M}+}$ & $111 \cdot 08$ & $52 \cdot 47$ & $11 \cdot 42$ & $19 \cdot 13$ & $17 \cdot 98$ & $9 \cdot 06$ & $5 \cdot 46$ & $-3 \cdot 50$ & -0.94 & $58 \cdot 61$ \\
\hline $\begin{array}{l}\text { CON } \\
\text { INF } \\
\text { B \& P } \\
\text { DIA } \\
\text { OTH }\end{array}$ & $\begin{array}{r}32 \cdot 93 \\
3 \cdot 85 \\
14 \cdot 24 \\
5 \cdot 54 \\
9 \cdot 99\end{array}$ & $\begin{array}{r}19 \cdot 81 \\
0 \cdot 21 \\
0 \cdot 03 \\
2 \cdot 00 \\
4 \cdot 74\end{array}$ & $\begin{array}{l}2 \cdot 80 \\
0 \cdot 81 \\
3 \cdot 24 \\
2 \cdot 29 \\
0 \cdot 62\end{array}$ & $\begin{array}{r}3 \cdot 01 \\
0 \cdot 30 \\
2 \cdot 89 \\
-0 \cdot 36 \\
2 \cdot 66\end{array}$ & $\begin{array}{r}3 \cdot 20 \\
1 \cdot 08 \\
2 \cdot 62 \\
-2 \cdot 58 \\
1 \cdot 23\end{array}$ & $\begin{array}{l}2 \cdot 75 \\
0 \cdot 43 \\
1 \cdot 91 \\
0.96 \\
0 \cdot 16\end{array}$ & $\begin{array}{l}2 \cdot 36 \\
0 \cdot 19 \\
0 \cdot 63 \\
0 \cdot 55 \\
1 \cdot 31\end{array}$ & $\begin{array}{r}-0 \cdot 12 \\
0.45 \\
2 \cdot 63 \\
1 \cdot 86 \\
-0.72\end{array}$ & $\begin{array}{r}-0.88 \\
0.38 \\
0.29 \\
0.82 \\
-0.01\end{array}$ & $\begin{array}{r}13 \cdot 12 \\
3 \cdot 64 \\
14 \cdot 21 \\
3 \cdot 54 \\
5 \cdot 25\end{array}$ \\
\hline Total & $66 \cdot 55$ & $26 \cdot 79$ & $9 \cdot 76$ & $8 \cdot 50$ & $5 \cdot 55$ & $6 \cdot 21$ & $5 \cdot 04$ & $4 \cdot 10$ & $0 \cdot 60$ & $39 \cdot 76$ \\
\hline $\begin{array}{l}\text { DAY } \\
\text { WK } \\
\text { MON } \\
1 Q \\
2 Q \\
3 Q \\
4 Q\end{array}$ & $\begin{array}{r}10 \cdot 94 \\
12 \cdot 33 \\
9 \cdot 75 \\
10 \cdot 67 \\
9 \cdot 28 \\
7 \cdot 26 \\
6 \cdot 39\end{array}$ & $\begin{array}{r}9.07 \\
7.45 \\
3.38 \\
3.98 \\
2.09 \\
1.34 \\
-0.27\end{array}$ & $\begin{array}{l}1 \cdot 83 \\
0 \cdot 82 \\
2 \cdot 08 \\
0 \cdot 82 \\
1 \cdot 19 \\
1 \cdot 73 \\
1 \cdot 57\end{array}$ & $\begin{array}{l}0 \cdot 28 \\
1 \cdot 74 \\
1 \cdot 38 \\
1 \cdot 35 \\
1 \cdot 65 \\
1 \cdot 22 \\
0 \cdot 90\end{array}$ & $\begin{array}{r}-0.81 \\
1 \cdot 14 \\
1.11 \\
1.58 \\
0.45 \\
-0.27 \\
2.00\end{array}$ & $\begin{array}{l}0.81 \\
0.82 \\
0.72 \\
0.96 \\
0.89 \\
1.13 \\
0.81\end{array}$ & $\begin{array}{r}0.46 \\
1.80 \\
1.07 \\
0.64 \\
0.74 \\
0.34 \\
-0.02\end{array}$ & $\begin{array}{r}-0.38 \\
-0.82 \\
0 \cdot 18 \\
0.91 \\
1 \cdot 65 \\
1 \cdot 40 \\
1 \cdot 15\end{array}$ & $\begin{array}{r}-0.32 \\
-0.62 \\
-0.17 \\
0.43 \\
0.62 \\
0.37 \\
0.25\end{array}$ & $\begin{array}{l}1 \cdot 87 \\
4 \cdot 88 \\
6 \cdot 37 \\
6 \cdot 69 \\
7 \cdot 19 \\
5 \cdot 92 \\
6 \cdot 66\end{array}$ \\
\hline Total & $66 \cdot 62$ & $27 \cdot 04$ & $10 \cdot 04$ & $8 \cdot 52$ & $5 \cdot 20$ & $6 \cdot 14$ & $5 \cdot 03$ & $4 \cdot 09$ & 0.56 & $39 \cdot 58$ \\
\hline $\begin{array}{l}\text { NEO } \\
\text { POST }\end{array}$ & $\begin{array}{l}33 \cdot 02 \\
33 \cdot 60\end{array}$ & $\begin{array}{r}19 \cdot 90 \\
7 \cdot 14\end{array}$ & $\begin{array}{l}4 \cdot 73 \\
5 \cdot 31\end{array}$ & $\begin{array}{l}3 \cdot 40 \\
5 \cdot 12\end{array}$ & $\begin{array}{l}1 \cdot 44 \\
3 \cdot 76\end{array}$ & $\begin{array}{l}2 \cdot 35 \\
3 \cdot 79\end{array}$ & $\begin{array}{l}3 \cdot 33 \\
1 \cdot 70\end{array}$ & $\begin{array}{r}-1 \cdot 02 \\
5 \cdot 11\end{array}$ & $\begin{array}{r}-1 \cdot 11 \\
1 \cdot 67\end{array}$ & $\begin{array}{l}13 \cdot 12 \\
26 \cdot 46\end{array}$ \\
\hline
\end{tabular}

When mortality is dissected by age at death, the proportion explained steadily rises throughout the year of infancy. Indeed, in the fourth quarter the computed mortality for the arbitrarily chosen baseline population is $-0 \cdot 27$, which is, of course, not significantly different from zero. Neonatal deaths, like stillbirths and congenital causes, give a $\mathrm{K}$ about three-fifths of the mean, while in the post-natal period more than three-quarters of the deaths are associated with adverse social conditions. 
Directing attention to the individual social indices, one notices the following:

For stillbirths, neonatal deaths, and congenital causes and other causes, both $G$ and $D$ have negative effects. Other things being equal, the equations indicate that the bigger the family and the greater the density of people on the site, the lower are the mortality rates in these categories. In a later communication it will be shown that the same thing is true for maternal mortality. In all cases the negative contribution of $D$ is coupled with a positive influence of $H$. Overcrowding in the home is still associated with increased rates in these, and indeed in all, the various divisions of infant mortality. The equations enable one to distinguish the separate effects of these two related aspects of town life. For postnatal deaths and for the three zymotic cause groups, crowding in the house and crowding on the site seem to act in the same direction. For stillbirths and deaths in early infancy, at a given degree of crowding in the home, the higher the density per acre the lower the death rate. This is one unexpected outcome of the equations that will require aetiological discussion.

Another unexpected result is the negative effect computed for the two indices of low income, $U$ and $P$, in the equation for diarrhoea. If these figures truly represent the facts, it would seem that, for equal degrees of overcrowding, family size, latitude, and employment of women, the better off the people in the borough the higher the death-rate from diarrhoea.

Three other negative figures appear. Two are associated with $\mathrm{P}$, and relate to deaths on the first day and in the third quarter. The other negative is for $\mathrm{L}$ in the fourth quarter, but the computed effect on the average mortality rate-namely, -0.02 -is so small that it can be taken as not significantly different from zero.

For the negative effect of $G$ in stillbirths, congenital and other causes, and neonatal deaths, there is a reasonable explanation available. The risk of stillbirth and of neonatal death is known to be higher for first births than for immediately subsequent parities. Thanks to the additional details at registration required under the Population Statistics Act of 1938, we now have comprehensive information about parity and age of mother in relation to all births, including stillbirths, and various tabulations of the new data have been published for 1939 and 1940. From the published figures it is possible to construct a table showing the relation of single stillbirths to single live births according to age of mother and parity of child, and the results are given in Table XII. In each case the sum of single stillbirths for 1939 and 1940 is given as a rate per 1,000 single live births for the same two years. Rates based on less than 20 deaths are excluded, and those based on less than $\mathbf{8 0}$ deaths are in italics. The Registrar-General's method of tabulation does not allow maternities resulting in multiple births to be included in the calculations, but the disturbing effects of this omission on the general picture will be very small.

The table shows that, for each age-group of mothers, the stillbirth rate is much higher among the firstborn than for second births. Thereafter it rises with increasing birth rank, but only at very high parities does the stillbirth rate approach that for first babies. For any given parity, the stillbirth rate increases with age of 
mother. The lower the value of $\mathrm{G}$ the larger the proportion of first births to total births. Low $\mathrm{G}$ also involves a higher average age of the mother at maternity. For both these reasons, $\mathrm{G}$ would be expected to have the negative association with stillbirths that is shown by the regression equation.

TABLE XII

Single Stillbirths Per 1,000 Single Live Births by Party and Age of Mother: England AND WALES, $1939-40$

\begin{tabular}{|c|c|c|c|c|c|c|c|c|c|c|c|c|}
\hline \multirow{2}{*}{$\begin{array}{l}\text { Age of } \\
\text { Mother }\end{array}$} & \multicolumn{12}{|c|}{ Order of Birth } \\
\hline & 1 & 2 & 3 & 4 & 5 & 6 & 7 & 8 & 9 & 10 & $11-14$ & All \\
\hline $\begin{array}{l}15-19 \\
20-24 \\
25-29 \\
30-34 \\
35-39 \\
40-44 \\
45-49\end{array}$ & \begin{tabular}{r|r}
.. & 27 \\
.. & 29 \\
.. & 39 \\
.. & 57 \\
. & 82 \\
.. & 113 \\
.. & 126
\end{tabular} & $\begin{array}{l}18 \\
18 \\
21 \\
27 \\
39 \\
59 \\
\end{array}$ & $\begin{array}{l}-23 \\
24 \\
31 \\
40 \\
57 \\
98\end{array}$ & $\begin{array}{l}\overline{31} \\
29 \\
35 \\
48 \\
59 \\
94\end{array}$ & $\begin{array}{l}\overline{29} \\
33 \\
38 \\
50 \\
77 \\
84\end{array}$ & $\begin{array}{l}- \\
34 \\
39 \\
51 \\
71 \\
93\end{array}$ & $\begin{array}{l}- \\
28 \\
42 \\
51 \\
72 \\
92\end{array}$ & $\begin{array}{r}- \\
\overline{60} \\
42 \\
55 \\
67 \\
115\end{array}$ & $\begin{array}{r}- \\
- \\
43 \\
62 \\
72 \\
136\end{array}$ & $\begin{array}{l}- \\
\overline{-} \\
61 \\
68 \\
71 \\
99\end{array}$ & $\begin{array}{l}- \\
\overline{-} \\
63 \\
68 \\
80 \\
97\end{array}$ & $\begin{array}{r}26 \\
26 \\
31 \\
39 \\
52 \\
71 \\
101\end{array}$ \\
\hline All & 40 & 25 & 30 & 38 & 45 & 48 & 52 & 57 & 66 & 70 & 77 & 36 \\
\hline
\end{tabular}

There are no similar recent data, on a nation-wide scale, to show how neonatal death rates vary with parity and age of mother. But there is abundant evidence that first births have a higher rate than those immediately next in parity. Burns, for example, in a study of infant and maternal mortality in the County of Durham from 1930 to 1936 (Burns, 1942) found that the neonatal death rate in different social groups varied with parity as follows:

\begin{tabular}{cccccccccc} 
Parity & & & & \multicolumn{4}{c}{$\begin{array}{c}\text { Other Manual } \\
\text { Workers }\end{array}$} & \multicolumn{2}{c}{$\begin{array}{c}\text { Non-Manual } \\
\text { Workers }\end{array}$} \\
1 & $\ldots$ & $\ldots$ & $39 \cdot 1$ & $\ldots$ & $\ldots$ & $28 \cdot 5$ & $\ldots$ & $\ldots$ & $34 \cdot 5$ \\
$2-3$ & $\ldots$ &. & $32 \cdot 2$ & $\ldots$ & $\ldots$ & $25 \cdot 3$ & $\ldots$ & $\ldots$ & $25 \cdot 7$ \\
$4-6$ & $\ldots$ & $\ldots$ & $44 \cdot 4$ & $\ldots$ & $\ldots$ & $34 \cdot 2$ & $\ldots$ & $\ldots$ & $20 \cdot 7$ \\
$7+$ &. &. & $51 \cdot 2$ & $\ldots$ & $\ldots$ & $47 \cdot 3$ & $\ldots$ & $\ldots$ & $21 \cdot 2$
\end{tabular}

She found that, at any given parity, neonatal mortality was high among the youngest mothers, decreased until the age-group 25-30, and thereafter increased with age of mother. Woodbury (1925), in a study of infant mortality between 1911 and 1916 in eight American cities, also found a higher neonatal mortality in first-born babies than among the succeeding parities. His figures for the first nine birthranks were: $54,39,42,36,40,40,40,49,47$. For the tenth and later parities the rate was 69. His figures for neonatal death by age of mother also seem to show a minimum in the age-group 25-30. Baird (1945) also found that first-born babies were the most and second babies the least liable to neonatal death. Since the difference in mortality between first and subsequent parities is less marked for 
neonatal deaths than for stillbirths, and since higher average age of mother (which is associated with low $G$ ) has a much more marked influence on stillbirths than on neonatal deaths, it would be expected that the effect of a given increment in reproduction rate would be much greater for stillbirths than for neonatal mortality. Table XI shows that the regression equations faithfully reproduce this aetiological differential.

Both Burns and Woodbury found that postnatal mortality was lowest in first babies and increased steadily with birth-rank. Woodbury gives mortality rate by parity for each month of infancy, and from his figures it is possible to calculate the ratio that mortality at all parities bears to mortality of first-born in the periods corresponding to $1 \mathrm{Q}$ (2nd and 3rd months), $2 \mathrm{Q}, 3 \mathrm{Q}$, and $4 \mathrm{Q}$ in Table $\mathrm{XI}$. The ratios are $1 \cdot 26,1 \cdot 54,1 \cdot 32$, and $1 \cdot 22$, showing a maximum in the second quarter. The figures for the effect of $\mathrm{G}$ in Table XI are also at a maximum in the second quarter.

The equations display a negative effect for $\mathrm{D}$ in relation to stillbirths, neonatal deaths, congenital causes, and other causes. A comparison of Table XI with Fig. 3 will show that it is precisely in these categories that mortality rates for London are lower than for any other types of locality. Now, London has a higher $D$ value than anywhere else in the country. The figure for the County of London is 90.4 nearly three times the mean of the county boroughs, and considerably higher than the largest individual value among the boroughs. London is also the most extensive built-up area, and there is a marked association between high $\mathrm{D}$ and large size of conurbation. This is brought out in Table XIII, which shows the unweighted

TABLE XIII

Means and Standard Deviations of Social Indices

\begin{tabular}{|c|c|c|c|c|c|}
\hline $\begin{array}{l}\text { Social } \\
\text { Index }\end{array}$ & -Unit of Measurement & $\begin{array}{c}\text { Unweighted } \\
\text { Mean }\end{array}$ & $\begin{array}{l}\text { Standard } \\
\text { Deviation }\end{array}$ & $\begin{array}{l}\text { Weighted } \\
\text { Mean }\end{array}$ & $\begin{array}{l}\text { Weighted Mean - } \\
\text { Unweighted Mean }\end{array}$ \\
\hline \multirow[t]{2}{*}{$\begin{array}{l}\mathbf{H} \\
\mathbf{U} \\
\mathbf{P} \\
\mathbf{F} \\
\mathbf{L} \\
\mathbf{G} \\
\mathbf{D}\end{array}$} & $\begin{array}{l}\% \text { families living more } \\
1 \text { person per room } \\
\% \text { men unemployed } \\
\% \text { males in Classes IV and V }\end{array}$ & $\begin{array}{c}27.49 \\
19.62 \\
35.72 \\
15.05 \\
2.40 \\
0.935\end{array}$ & $\begin{array}{c}9 \cdot 61 \\
9 \cdot 28 \\
6 \cdot 88 \\
12 \cdot 15 \\
1 \cdot 21 \\
0 \cdot 190\end{array}$ & $\begin{array}{c}28 \cdot 20 \\
19 \cdot 23 \\
36 \cdot 27 \\
17 \cdot 00 \\
2 \cdot 40 \\
0.959\end{array}$ & $\begin{array}{c}0.71 \\
-0.39 \\
0.55 \\
1.95 \\
0 \\
0.024\end{array}$ \\
\hline & $\begin{array}{lllll}\text { acre } & \ldots & \ldots & \ldots & \cdots\end{array}$ & $33 \cdot 66$ & $16 \cdot 20$ & $41 \cdot 36$ & $7 \cdot 70$ \\
\hline
\end{tabular}

and the weighted mean value of each social index in the county boroughs. As in Table IV, the difference between the two kinds of mean is a measure of the association between the index and population size. It will be seen that $\mathrm{H}$ (crowding in the house) tends to be only very slightly greater in large than in small boroughs. The difference between the two means -0.71 - is a small fraction of the unweighted 
mean, which is $27 \cdot 49$. Similarly, $P, F$, and $G$ are a little higher in the more populous boroughs, $\mathrm{L}$ is indifferent, and $\mathrm{U}$ is on the whole slightly excessive in the smaller municipalities. But D shows an excess of $7 \cdot 70$-nearly $23 \%$ - of its weighted over its unweighted mean. It is therefore quite highly associated with population size. Nor is this the whole story. Woolf and Waterhouse discussed the feasibility of an index expressing size of built-up area, but were unable to devise a suitable measure. They say:

"An index based on size of population does not meet the case. Birmingham, for example, would have a high index and Smethwick a,low one, although both are parts of the same built-up area, and any effect of high population such as greater prevalence of infection would presumably affect babies equally on both sides of the borough boundaries. The same considerations apply to such places as Manchester and its smaller neighbour Salford, to the Tyneside towns, and especially to the three county boroughs in the Greater London area. The only valid measure of the effect would be the population of the total conurbation. This would be difficult to determine without gross ambiguity."'

Now it happens that the index $D$ is a fairly good measure of size of built-up area. By inspection it is obvious that the small boroughs which are part of bigger conurbations tend to have considerably higher $\mathrm{D}$ values than isolated boroughs of comparable population. And it is easy to see why this should be so. In an isolated town, building development will thin out on the outskirts, whereas a small borough adjoining a bigger neighbour will be fully built up to the common boundary. In interpreting the role of $D$ in the various equations, one must bear in mind that it expresses two social phenomena-close packing of population and, less efficiently, size of conurbation.

Although the negative coefficients for D may have been unexpected, they are seen to be consistent with other data. The equations say that, after due allowance has been made for crowding in the house and other social differentials, the larger and more closely packed a conurbation the lower its rates for stillbirths, neonatal mortality, congenital causes and other causes. Fig. 3 shows that London, the largest and most closely packed area, has an exceptionally low rate for each of these categories of mortality. On the other hand, the $\mathrm{D}$ effect is positive for postnatal mortality, for infectious diseases and bronchitis and pneumonia, and especially for diarrhoea. In all these cases, London has a rate markedly above that for the rural areas. The population of London, on the whole, is better off than that of the county boroughs. In infectious diseases, and bronchitis and pneumonia, the equations attribute a positive influence to the poverty indices, $U$ and $P$. In both these cause groups, Fig. 3 shows that county boroughs have a higher mortality than London. But in diarrhoea, where the equation indicates a negative effect for the poverty indices, London has a higher mortality than county boroughs. Any reasonable aetiological explanations of the equations for the county boroughs will also account for the infant mortality pattern of Greater London.

It is now possible, and necessary, to attempt to translate the equations into aetiological language. The two most easy to interpret are those for INF and for $B$ and P. Table XI shows that in both these cause groups the indices for crowding 
( $H$ and $D)$, for poverty ( $U$ and P), for size of family (G), for work by women (F), and for latitude (L) are all positive. The data in Table XI are shown in Table XIV,

TABLE XIV

Mortality Rates associated with Social Indices Grouped into Aetiological Categories

\begin{tabular}{|c|c|c|c|c|c|c|c|c|c|}
\hline & & & $\begin{array}{c}\text { "Better- } \\
\text { off "Rate } \\
\text { K }\end{array}$ & $\begin{array}{c}\text { Crowding } \\
\text { H \& D }\end{array}$ & $\begin{array}{c}\text { Poverty } \\
\text { U \& P }\end{array}$ & $\begin{array}{c}\text { Size of } \\
\text { Family } \\
\mathbf{G}\end{array}$ & $\begin{array}{c}\text { Work by } \\
\text { Women } \\
\text { F }\end{array}$ & $\underset{\text { L }}{\text { Latitude }}$ & $\begin{array}{l}\text { Total } \\
\text { Expl. }\end{array}$ \\
\hline $\begin{array}{l}\text { IM } \\
\text { STI }\end{array}$ & $\begin{array}{l}. \\
.\end{array}$ & $\begin{array}{l}. . \\
. .\end{array}$ & $\begin{array}{l}26 \cdot 81 \\
25 \cdot 66\end{array}$ & $\begin{array}{r}10 \cdot 42 \\
0.06\end{array}$ & $\begin{array}{l}14 \cdot 10 \\
23 \cdot 01\end{array}$ & $\begin{array}{r}4 \cdot 02 \\
-7 \cdot 52\end{array}$ & $\begin{array}{l}6 \cdot 13 \\
2 \cdot 93\end{array}$ & $\begin{array}{l}5 \cdot 12 \\
0 \cdot 34\end{array}$ & $\begin{array}{l}39 \cdot 79 \\
18 \cdot 82\end{array}$ \\
\hline $\mathbf{I} \mathbf{M}+\mathbf{S}$ & & . & $52 \cdot 47$ & $10 \cdot 48$ & $37 \cdot 11$ & $-3 \cdot 50$ & $9 \cdot 06$ & $5 \cdot 46$ & $58 \cdot 61$ \\
\hline $\begin{array}{l}\text { CON } \\
\text { INF } \\
\text { B \& P } \\
\text { DIA } \\
\text { OTH }\end{array}$ & $\begin{array}{l}. \\
\cdots \\
\cdots \\
\cdots\end{array}$ & $\begin{array}{l}. . \\
. . \\
. . \\
. .\end{array}$ & $\begin{array}{r}19 \cdot 81 \\
0.21 \\
0.03 \\
2.00 \\
4 \cdot 74\end{array}$ & $\begin{array}{l}1 \cdot 92 \\
1 \cdot 19 \\
3 \cdot 53 \\
3 \cdot 11 \\
0 \cdot 61\end{array}$ & $\begin{array}{r}6 \cdot 21 \\
1 \cdot 38 \\
5 \cdot 51 \\
-2 \cdot 94 \\
3 \cdot 89\end{array}$ & $\begin{array}{r}-0.12 \\
0.45 \\
2.63 \\
1.86 \\
-0.72\end{array}$ & $\begin{array}{l}2.75 \\
0.43 \\
1.91 \\
0.96 \\
0.16\end{array}$ & $\begin{array}{l}2 \cdot 36 \\
0 \cdot 19 \\
0 \cdot 63 \\
0 \cdot 55 \\
1 \cdot 31\end{array}$ & $\begin{array}{r}13 \cdot 12 \\
3 \cdot 64 \\
14 \cdot 21 \\
3 \cdot 54 \\
5 \cdot 25\end{array}$ \\
\hline Total & . & .. & $\begin{array}{r}26 \cdot 79 \\
.\end{array}$ & $10 \cdot 36$ & $14 \cdot 05$ & $4 \cdot 10$ & $6 \cdot 21$ & $5 \cdot 04$ & $39 \cdot 76$ \\
\hline $\begin{array}{l}\text { DAY } \\
\text { WK } \\
\text { MON } \\
1 Q \\
2 Q \\
3 Q \\
4 Q\end{array}$ & $\begin{array}{l}. \\
\because \\
\because \\
\cdots \\
\cdots \\
\therefore\end{array}$ & $\begin{array}{l}. . \\
\therefore \\
. . \\
. . \\
. .\end{array}$ & $\begin{array}{r}9 \cdot 07 \\
7 \cdot 45 \\
3 \cdot 38 \\
3 \cdot 98 \\
2.09 \\
1 \cdot 34 \\
-0 \cdot 27\end{array}$ & $\begin{array}{l}1 \cdot 51 \\
0 \cdot 20 \\
1 \cdot 91 \\
1 \cdot 25 \\
1 \cdot 81 \\
2 \cdot 10 \\
1 \cdot 82\end{array}$ & $\begin{array}{r}-0.53 \\
2.88 \\
2.49 \\
2.93 \\
2 \cdot 10 \\
0.95 \\
2.90\end{array}$ & $\begin{array}{r}-0.38 \\
-0 \cdot 82 \\
0 \cdot 18 \\
0.91 \\
1.65 \\
1.40 \\
1 \cdot 15\end{array}$ & $\begin{array}{l}0.81 \\
0.82 \\
0.72 \\
0.96 \\
0.89 \\
1.13 \\
0.81\end{array}$ & $\begin{array}{r}0.46 \\
1 \cdot 80 \\
1 \cdot 07 \\
0.64 \\
0 \cdot 74 \\
0 \cdot 34 \\
-0.02\end{array}$ & $\begin{array}{l}1 \cdot 87 \\
4 \cdot 88 \\
6 \cdot 37 \\
6 \cdot 69 \\
7 \cdot 19 \\
5 \cdot 92 \\
6 \cdot 66\end{array}$ \\
\hline Total & & . & $27 \cdot 04$ & $10 \cdot 60$ & $13 \cdot 72$ & 4.09 & $6 \cdot 14$ & 5.03 & $39 \cdot 58$ \\
\hline $\begin{array}{l}\text { NEO } \\
\text { POST }\end{array}$ & .. &.. & $\begin{array}{r}19 \cdot 90 \\
7 \cdot 14\end{array}$ & $\begin{array}{l}3 \cdot 62 \\
6 \cdot 98\end{array}$ & $\begin{array}{l}4 \cdot 84 \\
8 \cdot 88\end{array}$ & $\begin{array}{r}-1 \cdot 02 \\
5 \cdot 11\end{array}$ & $\begin{array}{l}2 \cdot 35 \\
3 \cdot 79\end{array}$ & $\begin{array}{l}3.33 \\
1 \cdot 70\end{array}$ & $\begin{array}{l}13 \cdot 12 \\
26 \cdot 46\end{array}$ \\
\hline
\end{tabular}

with the social indices grouped into aetiological categories, and both tables should be consulted during the course of the discussion. It is reasonable to suppose that the mortality from these diseases will depend on two processes: (1) exposure to infection, which will determine the case-incidence; (2) case-fatality rate, which will vary with the stamina and resistance of the infected infants. Probability of infection will be positively associated with $\mathbf{H}$ (the crowding of the house), D (the size and density of the herd), and G, which measures the extra risk when the crowding is by other children rather than adults. There is some independent evidence on each of these points. Halliday (1928), in a study of measles in Glasgow, found that children in crowded tenements tended to be infected at pre-school age 
much more frequently than those living in good-class residential areas. The attack rate during the year of infancy in the industrial and poor wards was almost four times as great as in the residential wards. Wright and Wright (1942), studying the incidence of diphtheria, measles, and whooping-cough in London boroughs, found that a low mean age of infection was highly correlated with substandard housing, while the association with poverty was much lower. Cheeseman, Martin, and Russell (1939) gave reasons for attributing the rise in the age-incidence of diphtheria during the present century to the steady diminution of mean family size, with a consequent lessened exposure of infants to infection by other children; and the same arguments would doubtless apply to the other infectious diseases. It seems likely that the index $F$ is also partly a measure of increased exposure to infection. During the pre-war years covered by this study, babies whose mothers went to work in mill or pottery were mainly left in the care of neighbours. If Granny was available, she minded the baby, along with other babies who had no grannies. Such infants would be exposed during the day to an artificial loading of the $\mathrm{H}$ effect-crowding in the home-and the $\mathrm{G}$ effect-crowding by other children-with a consequent increased liability to infection.

Once infected, the baby's chance of survival would depend upon a number of circumstances, including: (a) its state of nutrition; $(b)$ the quality of the care and nursing it received; and $(c)$ its prenatal and postnatal history, and especially whether it was born prematurely.

All such effects would be quite efficiently measured by the poverty indices, $U$ and $P$. While there is a paucity of direct studies on the relation between nutrition in infants and their case-mortality from infectious diseases, there is abundant indirect evidence, and a consensus of opinion among medical authorities, that the nutritional aspect is of very great importance. This is shown, for example, in two recent statements by Cruickshank (1945) and Young (1945). Spence (1933), in an investigation of child health in Newcastle-on-Tyne, said:

\footnotetext{
"In my opinion, the main immediate cause of the apparent malnutrition of the city children is the physical damage done by infective diseases occurring in young children at susceptible ages, and under conditions which prevent satisfactory recovery. The main factors which promote and perpetuate this physical damage are probably: (a) the housing conditions which permit mass infections of young children at susceptible ages; (b) improper and inadequate diet, which prevent satisfactory recovery from their illnesses. It is probable that these two factors are of equal importance; but I would suggest that opinion on this matter should be reserved until a full inquiry, carried out by competent observers in a scientific manner, has studied the problem more closely."
}

It seems probable that premature babies will be less able than full-term infants to recover from infectious diseases; but here again direct evidence is scarce. There are several studies, including those quoted by Crosse (1945), showing that premature babies have a very high mortality during the neonatal period. Woodbury (1925) found that premature infants also had a $50 \%$ higher death-rate from respiratory diseases and a $120 \%$ higher rate from infectious diseases than babies born at full term. It will be shown below that prematurity is probably largely influenced by the poverty indices, $U$ and $P$, and relatively little by the crowding indices. It is 
also appreciably influenced by $\mathrm{F}$, so that part of the effect of $\mathrm{F}$ in the equations for INF and $B$ and $P$ may be ascribed to the deleterious effect of female labour, acting on the child through the mother.

In default of the full scientific inquiry asked for by Spence, the regression equations allow of an estimate of the relative importance of the various social agencies in relation to mortality from infectious diseases and bronchitis and pneumonia. From Tables XI and XIV it will be seen that in both cause groups the contribution of the poverty indices ( $U$ and $P$ ) is rather greater than that of the crowding indices ( $\mathrm{H}$ and $\mathrm{D})$, though if $\mathrm{G}$ is included as an element in the crowding complex the order is reversed. The relative influence of the various social agencies is more clearly brought out in Table $\mathrm{XV}$, where the contribution to the mean

TABLE XV

Percentages of "Explained" Deaths from Infectious Diseases and Bronchitis and PNeumonia associated with the Social Indices

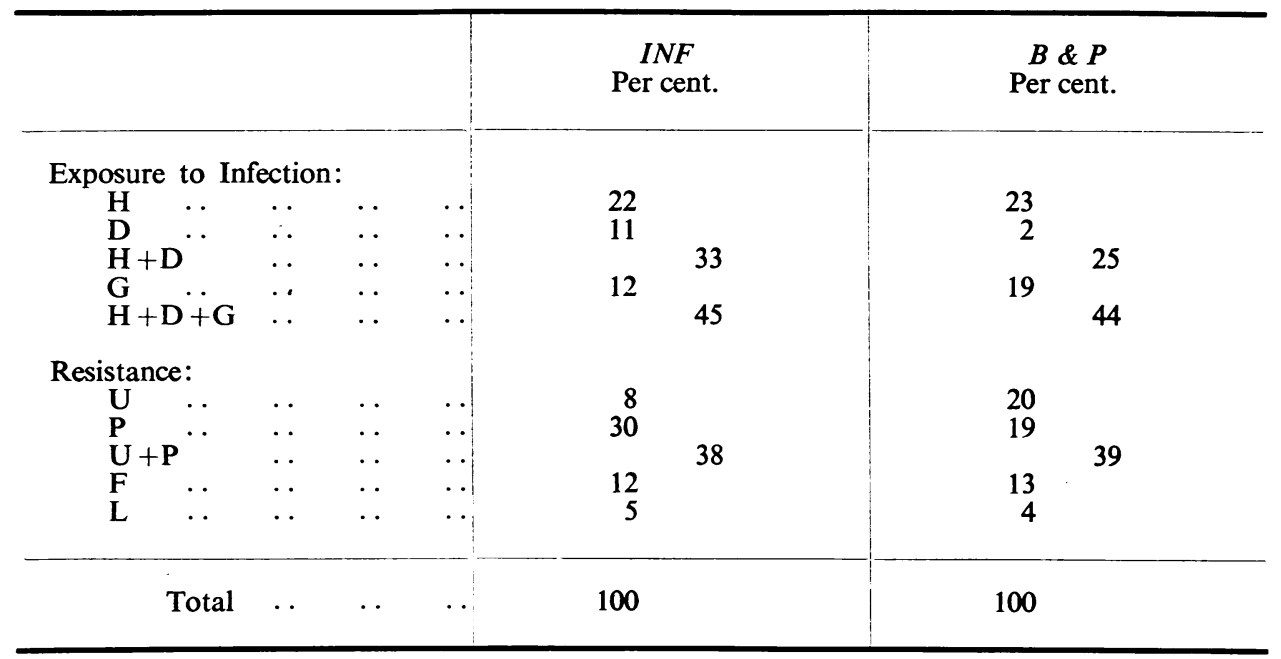

mortality of each index, as given in Table XI, is expressed as a percentage of the total explained mortality in the two cause groups. It will be seen that the indices expressing exposure to infection account for $44 \%$ and $45 \%$ of the respective mortalities, and those associated with resistance for $38 \%$ and $39 \%$. The conjecture of Spence, that the two aspects are of about equal importance, is supported by the equations. Within the exposure complex there is a difference between the two cause groups. In the infectious diseases, the size and density of the herd, expressed by $D$, is of more weight than in the respiratory diseases which, however, are more strongly influenced by $G$, infection by other children in the home. In the resistance complex, also, bronchitis and pneumonia appear to be the more strongly influenced by extreme poverty, as measured by U. All 
these differences are consistent with the known aetiology of these diseases, and with their relative mortalities in social classes and in the different types of locality, as shown in Figs. 1, 2, and 3. The F effect is about the same in each group, and the small $L$ effect will be discussed later.

The aetiological picture for stillbirths to be deduced from Tables XI and XIV is easily summarized. The small positive effect of $\mathrm{H}$ is almost entirely cancelled by the negative contribution of the other crowding index, D. F makes a relatively small though substantial contribution, adding about 3 to the mean mortality rate. But the big effects are large positive contributions by the poverty indices, $U$ and $P$, and a large negative effect associated with G. This is brought out in Table XIV. Stillbirths are only slightly influenced by housing conditions or latitude. The two big aetiological influences, pulling in opposite directions, are poverty, presumably mainly malnutrition, and size of family, small families being more subject to the biological risks attaching to first births and older mothers. There is also a substantial extra mortality when the mother works in industry. The positive influence of poverty outweighs the negative effect of G, so on the whole stillbirths are higher among the poor. But the disparity between rich and poor is much less than for infectious diseases, where poverty and large families act in the same direction with respect to mortality. Neonatal mortality and deaths from congenital causes present a similar picture, though in these cases housing and latitude are relatively much more important, and the negative influence of $G$ is considerably lower.

All these relationships are in accord with independent evidence or currently held specialist opinion. The modern view on the relation between maternal nutrition and child health is summed up by Young (1945) as follows:

"One of the most important developments within recent times relates to the critical influence
of maternal nutrition on the growth and health of the child before and after birth. It has
long been known that the pregnant state results in a marked increase in food requirements
and in a marked increase in weight. The greatest weight increase and the greatest demand for
food occur during the last months when the growth curves of the foetus and of the maternal
organs are at the steepest. It was for long believed that the foetus was protected against the
influence of undernourishment in an undernourished mother by the fact that it could draw
almost indefinitely on the mother's tissues. Animal-breeders, on the contrary, have long
recognized that the health and vigour of the offspring are critically dependent on the antenatal
nutrition of the mother animal and that abortion and premature birth and a weak litter may
result from relatively small quantitative depletion of essential nutritive elements. The
Toronto (1941), Oslo (1939), and People's League of Health (1942) investigations in London
suggest that the same holds true in the human field. Thus there is now a considerable body of
evidence to suggest that the standard of the antenatal nutrition of the mother influences the
incidence of prematurity and stillbirth and that in the poorer sections of the community
prematurity and stillbirth of antenatal origin are commonertithan in the higher economic grades
(Baird, 1945; Report on Infant Mortality in Scotland, 1943; Ebbs, Tisdall, and Scott, 1941).
At the same time more knowledge is required on these questions, and the same need applies
to the influence of maternal nutrition on lactation. There is clear evidence from animals
that the growth and output of the mammary glands are largely determined by the standard of
prenatal nutrition in the mother. On this fundamental question there is little precise informa-
tion on the human side."

To the references quoted by Young one may add a paper by Theobald (1946), who puts forward the reasons for regarding toxaemias of pregnancy, which so 
often result in stillbirth or premature birth of the infant, as largely determined by deficiencies in the maternal diet extending over the whole period of parturition.

The $\mathrm{F}$ effect in neonatal deaths is consistent with the figures for infant mortality by occupation of father in 1930-2, given by the Registrar-General (D.S., 1931). For example, in his comments on mortality among babies of textile workers, he says:

\begin{abstract}
" Skilled textile workers (Class III) recorded an infant mortality rate of $69 \cdot 7$, significantly above the class average of $57 \cdot 6$, and most of the excess was for deaths occurring within 4 weeks of birth, the rate being 38.6 per 1,000 , compared with 29.4 for Class III as a whole. The causes in excess were the congenital causes, premature birth and injury at birth. . . . The frequent employment of the wives of textile workers in the same occupations as their husbands is probably mainly responsible for this and also for the high rates of neonatal mortality in North III and IV."
\end{abstract}

No figures are available for stillbirths by occupation of father, but it is reasonable to suppose that increased liability to prematurity and injury at birth among babies of textile workers would entail also an enhanced rate of stillbirths.

It remains to account for the negative influence of $D$, the measure of close packing of population and size of conurbation. The only possible interpretation seems to be that in the more populous and densely settled conurbations the assistance and care available to a woman before, during, and immediately after childbirth are more than in a smaller and more scattered community. Maternity and child welfare centres will tend to be nearer, with better accommodation and staff. Care and attention at birth may also be better in quantity and quality, and probably there will be a larger proportion of babies born in hospitals and maternity homes. Certainly the marked superiority of Greater London as compared with the rest of the country, shown in Fig: 3-stillbirths about 8.5 per 1,000 below the England and Wales figure, and neonatal deaths about 6 units below-while perhaps partly attributable to relatively greater prosperity, must in the main be ascribed to better medical and social services. In contrast, neonatal mortality among the babies of coal-miners, who mainly live in small communities with bad medical and social facilities, is exceptionally high. In 1930-2 the figures were 38 per 1,000 for coalminers in Class III, and $\mathbf{4 0}$ for those in Classes IV and V, as compared with rates of $29 \cdot 4,31 \cdot 9$, and $32 \cdot 5$ for Classes III, IV, and V as a whole. In this connexion it must be remembered that a large proportion of neonatal deaths, whether ascribed to prematurity or not, occur among premature infants (Crosse, 1945). The chance that a miner's baby will die in its first month is more than $50 \%$ higher than the risk to a baby in London of like social class. This gives some idea of the possible reduction of neonatal mortality by improved nutrition and infant care. Such improved conditions might be expected to effect an even bigger reduction in stillbirths. Woolf and Waterhouse tried without success to construct an index measuring efficiency of maternal and child welfare services. It seems that D can be regarded as fulfilling, though probably not very efficiently, this function, at any rate so far as stillbirths and neonatal deaths are concerned.

The contributions of the various social indices to the miscellaneous group of diagnostic categories included in the OTH equation follow the same general 
pattern as in the STI and CON equations. Crowding has a small and poverty a large influence, and the effect of $G$ is negative. This group obviously consists largely of diseases of similar aetiology to stillbirths and the congenital causes.

The diarrhoea equation is the only one among the cause groups that seems to require a revision of current views on aetiology. All the indices presumably concerned with exposure to infection-H, F, G, and D-have substantial positive coefficients, and the two poverty indices- $U$ and $P$-are credited with a negative influence. It is of course known that diarrhoea spreads very rapidly among young babies, especially when they are massed in institutions. Where the equation gives an unexpected result is in the implication that, at equal degrees of exposure to infection, babies in poorer families are less likely than those in better-off homes to succumb to diarrhoea. If this were true, it would explain the high diarrhoea mortality in London. In considering the aetiology of diarrhoea, one must be prepared to modify or discard accepted conclusions. The various infective conditions lumped under this heading have changed enormously in relative importance in the last few decades. Formerly epidemics of infantile diarrhoea flared up in the late summer and autumn of hot dry years.' These have now almost ceased, and diarrhoea mortality is very little higher in the summer than in the winter. There was good evidence that the old epidemic diarrhoea was much more deadly to bottle-fed than to breast-fed babies. The consensus of clinical opinion seems to be that this is still true of the endemic diarrhoeal diseases now prevalent, but convincing statistically controlled proof is lacking. There is no evidence, either, to suggest that well-to-do babies are less frequently breast-fed than those in poorer homes. The indications are rather to the contrary. In view of the precision with which the regression equations for the other cause groups have fitted in with the independent evidence on aetiology, and of the agreement between the equation for diarrhoea and the high mortality in London, it seems that there is at least a serious case for investigation into the possibility that, at equal degrees of exposure, diarrhoea mortality is greater among the better-off.

The equations for mortality at the different periods of infancy tell the same general story as those for the cause groups. There is general agreement between the coefficients for the congenital causes group and those for neonatal deaths, and the zymotic cause groups and postnatal deaths show a similar parallelism. The negative index for $\mathrm{P}$ on the first day may be an expression of the incidence of deaths from injury at birth, which have an inverted class gradient. There is also a very small negative coefficient for $P$ in the third quarter. This is much more than counterbalanced by the positive influence ascribed to $U$, so that the poverty indices, taken together, act in the expected direction. It is possible that the $\mathbf{P}$ effect in the third quarter is associated with diarrhoea, although deaths from this cause are only about one-fifth of the total. This point might be cleared up by a special study of the present-day aetiology of infantile diarrhoea.

The next step is to integrate the aetiological picture of stillbirths and infant mortality as suggested by the equations regarded as a whole. In the case of 
stillbirths, the various social agencies can act on the child only through the mother; and this is largely the case also during the neonatal period. Now in stillbirths the important influences seem to be: (1) the biological risk, attaching with extra force to first births and to births to older mothers; (2) the poverty risk, mainly arising from maternal malnutrition; (3) the labour risk, when the mother is working in industry.

The biological risk, denoted by a negative coefficient for $\mathbf{G}$, can be diminished by increasing the size of families and lowering the age of maternity. As shown by the negative coefficient for $\mathrm{D}$ and the contrast between London and the rest of the country, it is also highly amenable to reduction by better social services and obstetric care. The extent to which this is possible is indicated by the results of Baird (1945), who is of the opinion that stillbirth rates can be reduced to 10 per 1,000 from the present level of round about 40 . The scope for improvement in the field of nutrition is shown by wartime experience, a most substantial reduction having been observed which must be attributed to improved feeding of mothers by the virtual abolition of unemployment, the raising of the wage standards of the lowest-paid workers, and the provision of special dietary supplements. The possibilities here are made the more striking by "the fact that wartime diets and wage rates still left much to be desired, and by no means all mothers availed themselves of the extra vitamin foods. The labour risk refers to the conditions under which pregnant women worked before the war, mainly in the textile and pottery industries. There is good ground for believing that better antenatal care and cessation of work at an adequate interval before the birth of the child can reduce this risk also.

The neonatal risks are similar to those for stillbirths, except that the housing index assumes some importance. This may perhaps be attributed to three aetiological effects: (1) The less efficient care that a baby, especially if weak or premature, would be able to receive in bad and overcrowded dwellings. (2) The risk of infection of the child itself. (3) The increased mortality risk to the baby if its mother is ill at the time of birth. The probable existence of such an effect on the child through the mother is indicated by the fact that death-rates attributed to prematurity are higher in winter than in summer, and that neonatal deaths seem to be positively associated with the prevalence of influenza (Registrar-General, Text, 1934).

High stillbirth and neonatal rates are almost certainly associated with high incidence of prematurity. If premature babies, and those full-time infants enfeebled at birth through maternal malnutrition, are more liable than more fortunately born infants to die of infectious diseases in the postnatal period, then part of the crowding and poverty coefficients for the infectious groups of diseases and for postnatal deaths must be assigned to malnutrition of the mother before birth and bad housing in the neonatal period. That adverse conditions prenatally and immediately after birth have a persistent influence in the life of the child long afterwards is shown by a special study made by the Registrar-General (Text, 1934), who found that 
winter-born children had an excess mortality over the summer-born of $14 \%$ in the first year of life and $42 \%$ in the second.

Babies who survive the ordeal of birth and the relatively sheltered neonatal period begin to be directly affected by their environment. Crowding in the house $(H)$, especially by other children, whether their own sibs (G) or their neighbours (F), increases their risk of infection. Any good effect associated with better medical and social care in large conurbations is more than neutralized by the action of the large, densely packed herd as an infective reservoir. But they are still subject to the influence of social conditions on their mothers. Not only do they carry the handicap of prematurity or feebleness if their mothers were overworked or malnourished, but they also suffer from past and current maternal malnutrition or illness in so far as these conditions determine whether the mother's milk shall be plentiful and of good quality, and whether they shall be breast-fed at all. Any social index which is important in stillbirths or neonatal deaths, through its effect directly on the mother, will continue to show a like though diminishing effect in the equations for the various categories of postnatal deaths.

With these considerations in mind, one can attempt an aetiological explanation of the latitude effect. Woolf and Waterhouse gave reasons for believing that $\mathrm{L}$, in the equations for infant mortality, is not an expression primarily of climate acting directly on the baby, but rather of the generalized poverty, which increases. in England and Wales as one travels north. If $L$ really denoted greater prevalence or severity of infectious diseases one. would expect it to have a high coefficient in the equations for POST and for INF, B and P, and DIA, and a low one for NEO, CON, and OTH. But Table XI shows that the contrary is the case. The L index has a big effect on neonatal deaths and on congenital and other causes-mainly non-infective conditions-and a small influence in the infantile infections. It bulks twice as important in the neonatal as compared with the postnatal period. In the first three months of life (NEO plus 1Q) it increases the mean rate by 3.97. In the successive quarters its contribution is 0.74 and 0.34 , fading to zero in the last three months of infancy. This is what one would expect of an index that expressed an aetiological determinant not affecting the baby directly, but acting on it through the mother. Since $L$ is of minor importance to the stillbirth rate, it must be an indication of something connected with birth or neonatal life. When the influence of all the other social indices is discounted there must be an extra hazard connected with being born in the north as compared with the south. This may plausibly be attributed to one or more of the following possibilities:

1. Greater incidence of maternal illness at childbirth, due to more severe climatic conditions. and/or lower standard of resistance among women arising from generalized poverty not fully measured by the other indices.

2. Greater unfitness of mothers for child-bearing, attributable to: (a) worse design, state of repair and equipment of the house not measurable by an index of crowding, resulting in greater physical strain of housework on the woman; (b) cumulative effects of female employment before and after marriage on physique of women; (c) effect of life-long malnutrition, and especially lack of vitamin D in the chronically poor, smoky northern towns, on reproductive system; 
(d) migration of healthier women to more prosperous areas, leaving an undue proportion of the less fit as mothers of next generation.

3. Less efficient care of mother and newborn child, due to bad household facilities, social traditions, and maternal efficiency, and/or to inferior medical and social circumstances. In so far as this explanation is true, $\mathrm{L}$ can be regarded as supplementing $\mathrm{D}$ as a measure of maternal and child care.

A final evaluation of these tentative suggestions cannot be made without special investigation. But, whatever the exact mechanism may be, latitude must be regarded primarily as an index of conditions acting on the baby through the mother. Any direct effect on the baby is probably of secondary importance.

From Tables XI and XIV one can form an estimate of the relative importance of the various social agencies with respect to the total loss of infant life. The chief indications are as follows:

1. For infant mortality, poverty, presumably mainly malnutrition, contributes about $14 \cdot 1$, bulking rather larger than crowding, which is responsible for about $10 \cdot 4$ out of the difference between the "better-off" and the mean rate.

2. In stillbirths, however, crowding is of little importance, while poverty adds about $23 \cdot 0$ to the rate.

3. In the IM+STI equation, measuring total reproductive wastage, poverty consequently appears nearly four times as important as housing. Elimination of malnutrition might be expected to reduce the combined mortality rate in county boroughs by about 37 units, and levelling up of housing by about 10.5 units.

4. When the other social indices are allowed for, infant mortality increases with mean family size, the negative effect in the neonatal period being more than : counterbalanced by the increased risk of infection during the remainder of the period of infancy. But when infant mortality is combined with stillbirths, the net $G$ effect is negative. If the mean family size could be increased without concomitant aggravation of overcrowding or poverty, one would expect a smaller and not a larger wastage of infant life.

5. The computed total rate at the "better-off" level is about $52 \cdot 5$, almost equally divided between stillbirths and infant mortality. This is less than half the observed rate of $111 \cdot 1$. More than half the mortality can be regarded as preventable.

It is of interest to inquire how closely the deductions from the equations fit in with wartime experience. The data do not allow of anything more than a very rough comparison. No figures are available for individual municipalities, but only a summary for the country as a whole. Nor is there any basis for assessing alterations in incidence of overcrowding and other social variables. It seems highly probable, however, that the most important change during the war was the levelling up of the standard of nutrition of the worst-off section of the population, by the virtual abolition of unemployment, the increase in earnings, and measures taken by the Ministry of Food. It is proposed, therefore, to compare the changes in mortality rates with those to be expected by the abolition of conditions of extreme 
poverty, as measured by the index U. The relevant data are shown in Table XVI. For each year there is given the stillbirth rate per 1,000 live births, the total infant mortality, and the neonatal and postnatal rates. It will be seen that stillbirth rates fell steadily, neonatal rates rose in 1940 and 1941 but otherwise showed a marked

TABLE XVI

Stillbirths and Infant Mortality in ENGland and Wales during the War

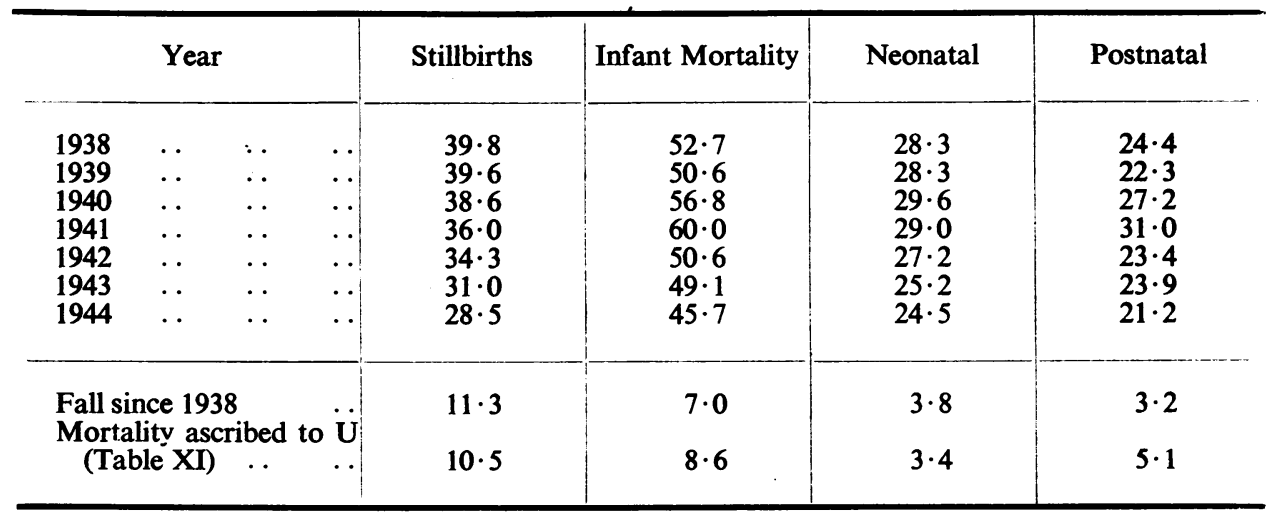

fall, and postnatal rates were more erratic, as would be expected from their dependence on various epidemic periodicities. At the foot of each column is the difference between the rates for 1938 and 1944, compared with the reduction, as shown in Table XI, to be expected by equating the index $U$ to zero. It will be seen that the two figures are remarkably close. Too much should not, of course, be made of this agreement, since the figures in Table XI refer to county boroughs at the average conditions for 1928-38, whereas the figures in Table XVI relate to the whole country during a time of profound social upheaval. Nevertheless Table XVI does seem to afford some additional evidence of the general validity of the method. of analysis used in this paper.

Further confirmation is provided in the valuable studies by Wright and Wright on the relation between social conditions in London boroughs and the incidence in young children of diphtheria, measles, tuberculosis, and whooping-cough (1942) and bronchitis and pneumonia (1945). They obtained correlation coefficients between social indices and mortality rates of orders of magnitude similar to those in Table VII, and their aetiological interpretations are also in line with those here presented. Closer comparison with their results is unfortunately not possible, since they relied mainly on correlation coefficients as measures of relationship. Comparison of Tables VII and XI will show that correlation coefficients are by no. means a correct indication of the relative influence of the various interrelated social agencies. In particular, an index, such as $G$ in the CON equation, may display a positive first order correlation, although the final regression coefficient is negative. The data for London would probably repay further analysis by the method of multiple regression. 
It must be emphasized that these aetiological deductions are not in any sense to be regarded as mathematically demonstrated. The equations show that the mortality of a county borough can be calculated, with a fairly high degree of precision, from the numerical values of its social indices. The interpretation of the equations depends not on mathematical but on social and medical considerations. The explanations sketched out above must be judged as scientific hypotheses, the criteria being:

Their internal consistency in relation to the phenomena of infant mortality.

Their degree of concordance with other independent evidence, and with clinical and social knowledge and experience.

The extent to which they throw light on observations taken from a wider fieldas, for example, the pattern of mortality in London.

The extent to which they suggest profitable lines of further investigation, and are confirmed by the results of such researches.

I wish to lay special stress on the last of these criteria. It will probably have been evident all through this paper that many of the topics touched on call for special ad hoc field investigations. It may fairly be claimed that the equations as a whole do present a consistent aetiological picture, in line with other evidence. But the full validification of many of the conclusions must await further surveys and inquiries. If the statistical analysis here reported has done nothing more than place the various aetiological problems of infant death into clear perspective, directing attention to aspects amenable to field investigation, it will have been amply worth while. In their statistical study of the incidence in London of some infectious diseases of childhood, Wright and Wright (1942) say that the statistical method " may be used to test deductively the general applicability of hypotheses based upon field observations, by finding how far inferences made from relatively restricted evidence are supported by statistical findings from larger sources of data." While fully agreeing with this, I would like to draw attention to the reverse procedure -the function of statistical studies in suggesting profitable topics for field inquiries. It is only by the close interweaving of statistical and field inquiries that a true science of social medicine can be built up. It is hoped that further papers in this series will report the results of field inquiries suggested by the statistical analysis described above.

No formal tests of " statistical significance " have been applied to the individual regression coefficients, because there seem to be no satisfactory tests available. The usual method, due to Fisher, is admitted by him to be faulty (Fisher, 1940). Woolf and Waterhouse overcame the lack by working out separate equations for each of the eleven years and showing that the values of the regression coefficients were so consistent from year to year as to establish their reliability with a high degree of probability. This procedure could have been adopted for the equations in the present paper, and some trial computations indicate that it would demonstrate the significance of the coefficients. But to have carried the process to completion 
would have meant spending twelve times as much time and labour on the computations-obviously a task not to be undertaken lightly.

A statistical result is said to be significant when it is believed that the finding is an inherent feature of the phenomena under discussion, that would regularly recur if further sets of observations could be taken keeping all relevant controllable conditions constant. It is customary to rely for establishing significance on a rule-of-thumb arithmetical test, whose outcome is an apparently highly precise numerical estimate of the probability that the result could not have occurred by chance. But since such probability estimates are never amenable to experimental verification, and since the assumptions on which the test depends for its validity are often of very doubtful applicability to the actual data, the appearance of precision is frequently spurious and even misleading. Current orthodox statistical doctrine seems to demand that, no matter how strong the collateral evidence may be in its favour, no result shall be accepted as significant until it has passed a test of this kind. This is surely putting the cart before the horse. Provided that the proponent of a result can show, to the satisfaction of any reasonable person acquainted with the subject under discussion, that his findings are firmly established, it is quite immaterial what kind of evidence he employs in the process. If a numerical probability test is easily available, and if the assumptions underlying such a test are not too much at variance with the nature of the data, such a test may as well be included in the evidence. Where, as in the present case; there is no satisfactory test, other means of validification must be employed.

The evidence for the reliability of the regression coefficients is of three kinds: (1) The internal consistency of the system of coefficients. (2) Their agreement with other statistical studies. (3) The fact that they fit in with a mass of aetiological evidence and with mortality data covering a much wider field in time and space than the county boroughs during 1928-38, and especially that they help to throw light on features of this wider experience not apparently otherwise explicable.

There is no need to labour any of these points. They have been fully elaborated in the aetiological discussion. If anybody, after reading so far, believes, for example that the negative coefficient of $G$ in stillbirths and neonatal deaths, and the positive values in the three infectious-cause groups, might have arisen from chance fluctuations, and that in another similar sample the signs might be reversed or the numerical values materially changed, then no formal test of significance is likely to shake that belief. For all such a test can establish is that, if one imagines another set of babies born in county boroughs in 1928-38, then the relation between their mortality and the social indices is not likely to be seriously different from what happened in the case of those who actually were born. If one wants to know whether the experience of these infants can be extrapolated to interpret the pattern of mortality in other years and places, the test of significance is of no assistance. The extended validity of the results would still need to be established by external evidence, such as that presented above. If that evidence is adjudged convincing, it will matter very little that statistical mathematics cannot provide a valid numerical test. 


\section{The Balance Sheet of Infant Deaths}

It remains to translate the regression equations into terms of actual infant deaths. Woolf and Waterhouse (1945) give detailed reasons for believing such a process is valid, at least to a first approximation, and it will certainly serve to make the meaning of the equations more concrete and vivid. But there is one rather important objection to using the equations as they stand. So far, all the county boroughs have been treated as of equal weight, whatever their population. The equations consequently relate to an imaginary conglomerate consisting of an equal number of babies from each county borough. But in considering the actual deaths in the county boroughs, one must take into account the fact that both the weighted means of mortality (Table IV) and of most of the social indices (Table XIII) tend to be rather higher than the unweighted figures. Larger boroughs incline on the whole to have rather worse social conditions and mortality rates than the smaller cities. In order to take this into account, one must use in the computations the weighted values given in Tables IV and XIII. To do so in detail would involve slight adjustments to all the figures shown in Table XI-all too small to make any difference to the aetiological picture. The only change that need be considered

TABLE XVII

Comparison of “Weighted" and "Unweighted" Estimates of Mortaltty Rates in “BeTter-OFF" PopUlation

\begin{tabular}{|c|c|c|c|c|c|c|c|}
\hline & & & $\begin{array}{l}\text { Weighted } \\
\text { Mean }\end{array}$ & $\begin{array}{l}\text { Explained } \\
\text { Mortality }\end{array}$ & Weighted K & Unweighted $\mathrm{K}$ & Difference \\
\hline $\begin{array}{l}\text { IM } \\
\text { STI }\end{array}$ & $\begin{array}{l}. \\
.\end{array}$ &.. & $\begin{array}{l}70 \cdot 35 \\
43 \cdot 58\end{array}$ & $\begin{array}{l}41 \cdot 50 \\
17 \cdot 79\end{array}$ & $\begin{array}{l}28 \cdot 85 \\
25 \cdot 79\end{array}$ & $\begin{array}{l}26 \cdot 81 \\
25 \cdot 66\end{array}$ & $\begin{array}{l}2 \cdot 04 \\
0 \cdot 13\end{array}$ \\
\hline $\begin{array}{l}\text { IM }+ \text { STI } \\
\text { CON } \\
\text { INF } \\
\text { B \& P } \\
\text { DIA } \\
\text { OTH }\end{array}$ & $\begin{array}{l}I \\
\cdots \\
\cdots \\
\cdots \\
\cdots\end{array}$ & $\begin{array}{l}. . \\
. . \\
. . \\
. .\end{array}$ & $\begin{array}{c}113.93 \\
33.05 \\
4.66 \\
15.44 \\
7.03 \\
10.7\end{array}$ & $\begin{array}{r}59 \cdot 29 \\
13.08 \\
3.97 \\
14 \cdot 83 \\
4 \cdot 33 \\
5 \cdot 23\end{array}$ & $\begin{array}{r}54 \cdot 64 \\
19 \cdot 97 \\
0.69 \\
0.61 \\
2.70 \\
4.94\end{array}$ & $\begin{array}{r}52 \cdot 47 \\
19 \cdot 81 \\
0 \cdot 21 \\
0 \cdot 03 \\
2 \cdot 00 \\
4 \cdot 74\end{array}$ & $\begin{array}{l}2 \cdot 17 \\
0 \cdot 16 \\
0 \cdot 48 \\
0 \cdot 58 \\
0 \cdot 70 \\
0 \cdot 20\end{array}$ \\
\hline $\begin{array}{l}\text { DAY } \\
\text { WK } \\
\text { MON } \\
1 Q \\
2 Q \\
3 Q \\
4 Q\end{array}$ & $\begin{array}{l}. \\
\therefore \\
\cdots \\
\therefore \\
\therefore \\
\therefore\end{array}$ & $\begin{array}{l}. . \\
. \\
. . \\
. \\
. \\
.\end{array}$ & $\begin{array}{r}11 \cdot 12 \\
11 \cdot 96 \\
9 \cdot 82 \\
11 \cdot 53 \\
10 \cdot 50 \\
8 \cdot 22 \\
7 \cdot 20\end{array}$ & $\begin{array}{l}1 \cdot 83 \\
4 \cdot 61 \\
6 \cdot 46 \\
7 \cdot 15 \\
7 \cdot 80 \\
6 \cdot 42 \\
7 \cdot 03\end{array}$ & $\begin{array}{l}9 \cdot 29 \\
7 \cdot 35 \\
3 \cdot 36 \\
4 \cdot 38 \\
2 \cdot 70 \\
1 \cdot 80 \\
0 \cdot 17\end{array}$ & $\begin{array}{r}9 \cdot 07 \\
7 \cdot 45 \\
3 \cdot 38 \\
3 \cdot 98 \\
2 \cdot 09 \\
1 \cdot 34 \\
-0 \cdot 27\end{array}$ & $\begin{array}{r}0.22 \\
-0.10 \\
-0.02 \\
0.40 \\
0.61 \\
0.46 \\
0.44\end{array}$ \\
\hline $\begin{array}{l}\text { NEO } \\
\text { POST }\end{array}$ & $\begin{array}{l}. \\
\cdots\end{array}$ & $\begin{array}{l}. . \\
. .\end{array}$ & $\begin{array}{l}32 \cdot 90 \\
37 \cdot 45\end{array}$ & $\begin{array}{l}12 \cdot 90 \\
28 \cdot 40\end{array}$ & $\begin{array}{r}20 \cdot 00 \\
9.05\end{array}$ & $\begin{array}{r}19 \cdot 90 \\
7 \cdot 14\end{array}$ & $\begin{array}{l}0 \cdot 10 \\
1.91\end{array}$ \\
\hline
\end{tabular}


is in the value of $K$, the computed mortality rate at the arbitrary " better-off" level. Table XVII gives for each equation the weighted mean, the mortality explained by substituting in the equation the weighted average for each social index, and the weighted $\mathrm{K}$. The unweighted $\mathrm{K}$ is given for comparison, together with the difference. It will be seen that weighting makes no material amendment to the results for stillbirths and neonatal deaths. For total infant mortality, the $\mathrm{K}$ value is raised by about 2 units, almost all confined to the postnatal period and to the three zymotic-cause groups, the biggest increase being observed in diarrhoea. Size of population is obviously a social variable that must be taken into account in order to obtain an undistorted picture of the aetiology of deaths from infection, even among the better-off strata. It will be seen also that the weighted $\mathrm{K}$ figures for cause groups and periods are probably more realistic than the unweighted values. The negative sign for the $4 \mathrm{Q}$ equation is reversed, and the very low figures for INF and B and $P$ are raised to a more likely level.

The balance sheet of infant deaths is shown in Table XVIII. In each category of mortality the total number of deaths in the county boroughs during the elevenyear period is given, rounded off to the nearest hundred, together with the "Unexplained " deaths, the computed number that would have been expected if each social index had been at the " better-off" level. The difference between the total and the unexplained deaths is divided up according to the calculated influence of the various social agencies. Thus, in the first column relating to total infant mortality, the estimate of lives that would have been saved by the elimination of crowding is 25,700; by elimination of poverty, 32,700; and so on. In the stillbirth column the minus signs indicate that reduction of the size of family and of crowding to the better-off standard, keeping other conditions unchanged, would have been expected to lead to more deaths. But this was of course counterbalanced by the poverty index. Columns 4 and 5 give infant mortality divided into neonatal and postnatal periods. The remaining columns give cause groups. In view of the similarity of their equations, infectious diseases and bronchitis and pneumonia have been combined. Out of the 266,300 stillbirths and infant deaths 138,600 , or more than half, are to be regarded as having been preventable by improvement in social conditions, and, of these, 86,300 , or more than three-fifths, could have been averted by raising earnings. Over 30,000 neonatal deaths and 66,000 postnatal deaths are calculated to have been preventable, the latter figure including over 44,000 deaths from infectious diseases and bronchitis and pneumonia.

The equations have been used to give an estimate of mortality at one postulated social level-the " better-off," as defined above. They can also be employed to calculate the expected mortality of any other social stratum, as defined by arbitrarily fixed values of the social indices. Two sutch strata are of special interest - the poorly paid crowded section of the working class, and those living permanently at the level of pre-war unemployment relief. For the first of these, both $\mathbf{H}$ and $\mathbf{P}$ must be equated to $100 \%$, and $U$ to zero; for the second, H, P, and U must each be put at $100 \%$. Plausible values must also be chosen for the other indices. The 


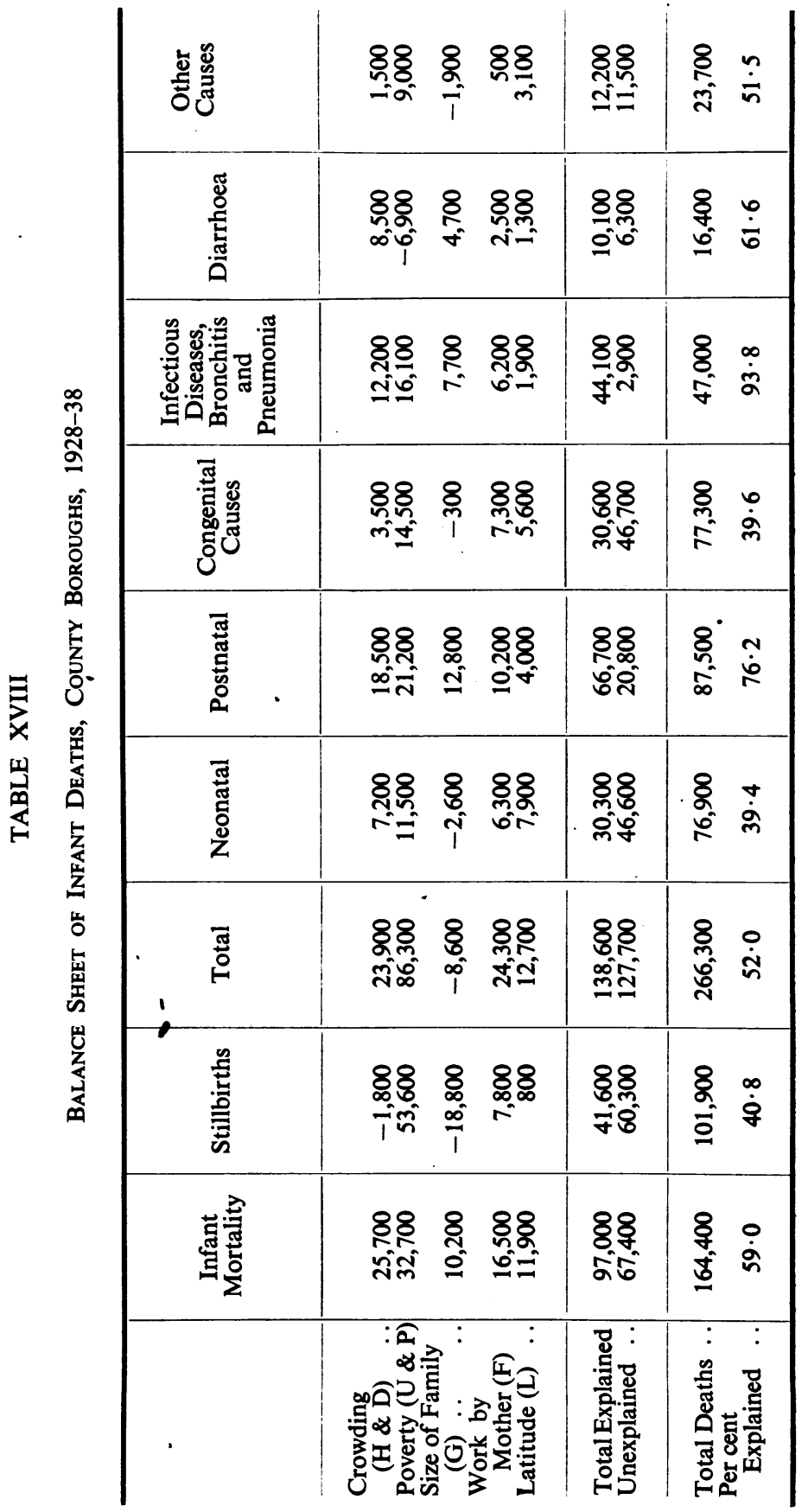


following values of the indices have been taken to define these two social levels:

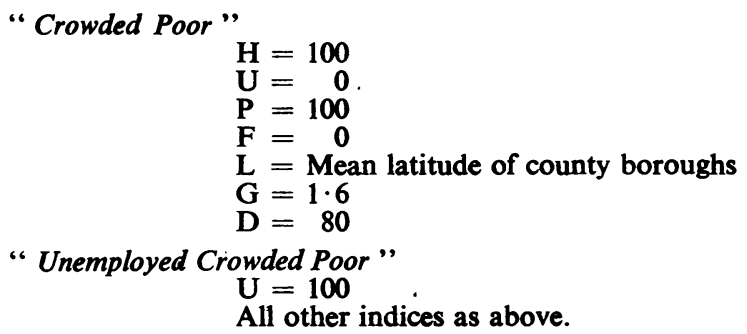

TABLE XIX

estimated Mortality Rates in Crowded Poor and Unemployed Crowded Poor Strata of Population

\begin{tabular}{|c|c|c|c|c|c|c|}
\hline & \multirow{2}{*}{$\because$ Better-off" } & \multirow[b]{2}{*}{$\begin{array}{c}\text { Weighted } \\
\text { Mean }\end{array}$} & \multirow[b]{2}{*}{$\begin{array}{l}\text { Crowded } \\
\text { Poor }\end{array}$} & \multirow{2}{*}{$\begin{array}{l}\text { Unemployed } \\
\text { Crowded } \\
\text { Poor }\end{array}$} & \multicolumn{2}{|c|}{$\begin{array}{l}\text { Percentage of Weighted } \\
\text { Mean }\end{array}$} \\
\hline & & & & & $\begin{array}{l}\text { Crowded } \\
\text { Poor }\end{array}$ & $\begin{array}{l}\text { Unemployed } \\
\text { Crowded } \\
\text { Poor }\end{array}$ \\
\hline $\begin{array}{ll}\text { IM } & \ldots \\
\text { STI }\end{array}$ & $\begin{array}{l}28 \cdot 9 \\
25 \cdot 8\end{array}$ & $\begin{array}{l}70 \cdot 4 \\
43 \cdot 6\end{array}$ & $\begin{array}{l}97 \cdot 8 \\
37 \cdot 7\end{array}$ & $\begin{array}{r}141 \cdot 0 \\
91 \cdot 1\end{array}$ & $\begin{array}{r}139 \\
86\end{array}$ & $\begin{array}{l}200 \\
209\end{array}$ \\
\hline $\mathbf{I M}+\mathbf{S T I}$ & $53 \cdot 7$ & $114 \cdot 0$ & $135 \cdot 5$ & $232 \cdot 1$ & $119^{\circ}$ & 204 \\
\hline $\begin{array}{l}\text { CON .. } \\
\text { INF } \\
\text { B \& D } \\
\text { DIA ... } \\
\text { OTH .. }\end{array}$ & $\begin{array}{r}20.0 \\
0.7 \\
0.6 \\
2.7 \\
4.9\end{array}$ & $\begin{array}{r}33 \cdot 1 \\
4 \cdot 7 \\
15 \cdot 4 \\
7 \cdot 0 \\
10 \cdot 2\end{array}$ & $\begin{array}{r}37.1 \\
9.4 \\
28.9 \\
12.8 \\
9.6\end{array}$ & $\begin{array}{l}52 \cdot 4 \\
10 \cdot 9 \\
43 \cdot 6 \\
11 \cdot 0 \\
23 \cdot 1\end{array}$ & $\begin{array}{r}112 \\
201 \\
187 \\
182 \\
94\end{array}$ & $\begin{array}{l}159 \\
234 \\
283 \\
156 \\
227\end{array}$ \\
\hline $\begin{array}{l}\text { NEO } \\
\text { POST }\end{array}$ & $\begin{array}{r}19 \cdot 9 \\
9 \cdot 0\end{array}$ & $\begin{array}{l}32 \cdot 9 \\
37 \cdot 5\end{array}$ & $\begin{array}{l}36 \cdot 6 \\
61 \cdot 2\end{array}$ & $\begin{array}{l}53 \cdot 8 \\
87 \cdot 2\end{array}$ & $\begin{array}{l}111 \\
163\end{array}$ & $\begin{array}{l}164 \\
233\end{array}$ \\
\hline
\end{tabular}

The computed mortality rates at these social levels are shown in Table XIX, and compared with the " better-off" figure (weighted K) and the weighted mean for county boroughs. The rates for the crowded poor and the unemployed crowded poor are also shown as percentages of the weighted mean.

It will be seen that the poor have a computed infant mortality rate of $97 \cdot 8$, being $24 \cdot 4$, or $39 \%$, above the mean. Owing to their postulated larger size of family, their expected stillbirth rate is $37 \cdot 7$, substantially lower than the mean. Their computed total reproductive loss is $119 \%$ of the average. But the unemployed 
poor show both an infant mortality and a stillbirth rate of double the mean figure. The excess mortality among the poor and unemployed poor occurs chiefly in the postnatal period and in the infectious and bronchitis and pneumonia cause groups. In the category of other causes, extreme poverty, as measured by $U$, has the effect of doubling the computed rate. Bronchitis and pneumonia, and to a lesser extent infectious diseases and congenital causes, also show a material rise with increase in degree of poverty. Table XIX may usefully be compared with Table IV. The highest county borough showed an infant mortality of $97 \cdot 6$, closely similar to the figure for the crowded poor. The lowest rate was 41.9. Since even the most prosperous county borough contains a substantial proportion of crowded, low-paid, and unemployed inhabitants, and the most badly off borough has many comparatively prosperous families, the extremes of the rates in individual boroughs cannot be expected to display the full range of mortality risks between the various strata of the population. The ratio of the best to the worst county borough for infant mortality is $2 \cdot 3$; the range between " better-off" and "unemployed crowded poor" in Table XIX gives a ratio of 4.9:1. For stillbirths the corresponding figures are: observed ratio among boroughs, $2 \cdot 1$; calculated ratio between social extremes, 3.5. The range of variation shown in Table XIX is of the order of magnitude one would infer from a study of Table IV, and a knowledge of the mixed social composition of all the county boroughs.

The big differences between the computed mortality rates for the "crowded poor" and the " unemployed crowded poor" is noteworthy. It indicates that, below a given level, small decreases in income, involving depreciation in the level of nutrition and other human needs, have disproportionately large effects in increasing mortality, and pręsumably also in adversely affecting the physique and stamina of the survivors. Conversely, any effort at social betterment may be expected to have the greatest effect in reducing mortality and morbidity if it is preferentially applied to raising the standards of the most unfortunate section of the population. The difference between the last two columns in Table XIX is a sufficient explanation of the dramatic reduction in stillbirth and infant mortality rates during the war, when limited resources were so used as to reduce the pre-war disparity in satisfaction of biological needs among the different income grades of the population.

It is important to bear in mind the limitations of the regression method as well as its powers. The equations can take cognizance only of differences between places. Any relevant circumstances that affect all places more or less equally cannot enter into the calculations. Since 1900 , infant mortality has fallen by about two-thirds-from round about 150 to round about 50 . But the relative disparity between the best and the worst places, or between the social classes, has remained remarkably steady. The equations can display how, at one particular period, differences in mortality rates are bound up with variations in social conditions. They cannot directly deal with the effect of the changing social background in lowering the level of mortality for rich and poor alike. The high degree of statistical 
explanation afforded by the equations indicates that, at any given general level of social, cultural, and sanitary progress, the differences in mortality between different strata of the population are largely conditioned by disparities in material environment, using that word in its broadest sense, and could presumably be diminished by levelling up of social conditions. But social agencies that must have affected the general level of mortality at different times, such as improvements in medical and social services, in education and nutrition and mothercraft, and possible biological changes in infective agents of disease, cannot appear in the equations directly. In this paper an attempt has been made, by comparisons between county boroughs and other types of area, to obtain some estimate of the potency of these general social agencies. It is beyond question that conscious social effort, whether direct as in maternity and child welfare services, or indirect as in universal education, has played a major part in diminishing loss of infant life, and that there is scope for further improvement in the future. But there is also abundant evidence that, at any given time in the past, variations from the general level of mortality were associated with crowding, malnutrition, industrial employment of women, and size of family, with relative effects qualitatively if not quantitatively similar to those obtaining in county boroughs during 1928-38. In this sense the equations have a validity outside the places and period to which they primarily relate. To reduce infant mortality to the unavoidable minimum it is necessary both to improve the general social, medical, and sanitary background and to ensure to each mother and baby the best possible material chance by levelling up social and economic conditions. For the immediate future, it is probable that the equations are a fairly reliable quantitative guide to the degree of reduction in infant deaths to be expected by alteration of this or that feature of the social environment. Similar equations calculated ten or twenty years hence might give different values to the coefficients associated with each social agency: But so long as disparities exist in environment at different social levels, it seems likely that there will continue to be differences in mortality rates bound up with variations in standards of housing, nutrition, and other relevant conditions, acting for each category of mortality in the direction indicated by the regression equations.

\section{SUMMARY}

1. Infant mortality in England and Wales is analysed by certified cause and by age at death. Comparative mortality rates, similarly analysed, are given for the Registrar-General's five Social Classes. Another set of comparisons, which also covers stillbirths, is made between Greater London, county boroughs, other urban districts, and rural districts. The aetiological implications of the data are discussed, attention being directed to points appearing to call for further investigation, such as the relatively low rates for stillbirths, neonatal deaths and deaths from congenital causes, and the relatively high mortality from diarrhoea in London as compared with the remainder of the country. 
2. Multiple regression equations have been calculated showing the relation between mortality rates and seven indices of social conditions in county boroughs over the eleven-year period 1928 to 1938 . The indices used are:

$\mathrm{H}$ : Percentage of families living more than one person per room.

$\mathrm{U}$ : Average monthly percentage of insured males unemployed.

P: Percentage of occupied males in the Registrar-General's Social Classes IV and $\mathrm{V}$ (semi-skilled and unskilled trades).

F: Percentage of females aged 14 and over employed in manufacture.

L: Degrees of latitude north of $50^{\circ} 30^{\prime}$.

G: Gross reproduction rate.

D: A weighted index of persons per acre.

A separate equation is given showing the relation between this set of social indices and each of the following mortality rates per 1,000 live births: all infant deaths; stillbirths; infant deaths plus stillbirths, representing the total wastage of life during birth and infancy.

Cause Groups: Congenital causes; infectious diseases; bronchitis and pneumonia; diarrhoea; other causes.

Age at Death: First day; rest of first week; rest of first four weeks; rest of first quarter; second quarter; third quarter; fourth quarter.

All the equations have a high degree of statistical significance.

3. From these equations, estimates are computed of the expected mortality rates among the "better-off" stratum of the population in county boroughs, comprising that section of the community for which the values of $\mathrm{H}, \mathrm{U}, \mathrm{P}, \mathrm{F}$, and $\mathrm{L}$ are zero, $G$ is $\mathbf{0 . 6}$, and $D$ is 20 . The combined infant mortality and stillbirth rate at this social level is estimated at about $52 \cdot 5$-less than half the average rate of about 111 obtaining in county boroughs.

4. For each category of mortality the contribution is estimated that each of the social indices makes to the difference between the "better-off" rate and the rate actually experienced.

5. The aetiological conclusions that would seem to follow from these figures are stated and discussed. They include the following:

(a) Poverty (probably mainly malnutrition) and crowding are of approximately equal importance in infant mortality. But crowding is relatively unimportant in stillbirths, whereas poverty has a very big effect. For the combined rate, therefore, poverty is much the more influential, making an estimated contribution of about 37 as against $10 \cdot 5$ attributable to crowding.

(b) At equal degrees of crowding and poverty, stillbirth and neonatal deathrates decrease with increasing size of family. This is in line with the fact that first births are known to carry an excess risk in these categories of mortality. In postnatal deaths and in all the zymotic-cause groups, larger families involve higher rates, because of the increased risk of infection of the baby by its elder sibs. 
(c) For the infectious diseases and the bronchitis and pneumonia cause groups, mortality increases with increased crowding (exposure to infection) and poverty (lessening of resistance). In diarrhoea, mortality increases with crowding, but at equal degrees of crowding seems to be greater for the better-off than the poor. This is in line with the high diarrhoea rate in London.

(d) Stillbirths and neonatal mortality tend to be lower in more densely populated and larger conurbations than in smaller communities. This is also in line with the comparative figures for London, and is attributed to the better social and medical care available in the larger places.

(e) The disparity between well-off, and poor is much greater for postnatal deaths, in which bad social conditions and large family size both act to increase mortality, than in stillbirths and neonatal deaths, where poverty and large family size act in opposite directions.

$(f)$ The latitude effect is so distributed that it appears to be an expression of influences acting on the child at birth through the mother. Possible social and aetiological explanations are discussed.

(g) Industrial employment of women seems to be associated with increases in all categories of mortality. The social aetiology is discussed.

(h) The larger the family size the higher the mortality rate among live-born infants. But large family size decreases the stillbirth rate so much that it more than cancels the increase in infant mortality. If the reproductive rate could be increased keeping other social conditions unchanged, then a decrease would be expected rather than an increase in the rate of wastage of infant life.

6. The fall in stillbirth and infant mortality rates from the 1938 level during the war period is of the order of magnitude to be expected from the levelling up of nutritional standards among the worst-off section of the population.

7. A balance sheet is given relating the actual numbers of stillbirths and of infant deaths in the various categories to the social influences defined by the seven indices.

8. The estimated mortality rate (infant mortality plus stillbirths) in the " crowded poor" section of the population of county boroughs is computed as about 136, and of the " unemployed crowded poor" about 232. The latter figure is more than twice the mean rate. Detailed comparisons are given between computed rates at these social levels and that of the "better-off" section of the community.

9. The scope and limitations of the multiple regression method are discussed, and the need for field research is emphasized.

My thanks are due to Miss Marie Bauer for her assistance with much of the computational work, and to the Rockefeller Foundation for the grant that made her services available out of an allocation for research work in Professor Lancelot Hogben's Department; to the Halley Stewart Trust for a grant for mechanical computing equipment; and to Professor Lancelot Hogben, F.R.S., for his constant interest and support. 


\section{REFERENCES}

Baird, D. (1945). J. Obstet. Gynaec. Brit. Emp., 52, 217, 339.

Burns, C. M. (1942). Infant and Maternal Mortality, Durham.

Charles, E. (1938). Article in Pólitical Arithmetic, ed. Hogben, L. London.

Cheeseman, E. A., Martin, W. J., and Russell, W. T. (1939). J. Hyg., Camb., 39, 181.

Crosse, V. M. (1945). The Premature Baby, London.

Cruickshank, R. (1945). Arch. Dis. Childh., 20, 145.

Ebbs, J. H., Tisdall, F. F., and Scott, W. A. (1941). J. Nutrit., $22,515$.

Fisher, R. A. (1940). Ann. Eugen., 10, 422.

Halliday, J. L. (1928). Med. Res. Cncl. Sp. Rep. Ser., No. $120 . \quad$ London.

Orr, J. B., et al. (1943). Infant Mortality in Scotland, H.M.S.O., Edinburgh.

Registrar-General. All references give date to which report refers, not date of publication. Abbreviations: A.R., Annual Review; D.S., Decennial Supplement (Occupational Mortality); Text, Text Volume of Annual Review.

Spence, J. C. (1933). Annual Report, Min. of Health, 214. London.

Theobald, G. W. (1946). J. Obstet. Gynaec. Brit. Emp., 53, 17.

Woodbury, R. M. (1925). Causal Factors in Infant Mortality, Children's Bureau, Washington, D.C.

Woolf, B., and Waterhouse, J. (1945). J. Hyg., Camb., 44, 67.

Wright, G. P., and Wright, H. P. (1942). Ibid., 42, 451.

Youn (1945). Ibid., 44, 15.

Young, J. (1945). Med. Off., 74, 119; 127. 


\section{CORRECTION}

The reference in the top left-hand corner of the article by Barnet Woolf in the April issue of this journal was erroneously printed Brit. J. soc. Med. (1947), 2, 73-125. This should, of course, have been : Brit. J. soc. Med. (1947), 1, 73-125. The references on pages 126 and 135 were similarly misprinted. 